Portland State University

PDXScholar

Summer 8-5-2019

\title{
"What About the Men? Investigating Alcohol Consumption, Masculinities, and Risky Sex in Peri- Urban Eswatini
}

Aaron Jackson Levine

Portland State University

Follow this and additional works at: https://pdxscholar.library.pdx.edu/open_access_etds

Part of the African Studies Commons, and the Gender and Sexuality Commons Let us know how access to this document benefits you.

Recommended Citation

Levine, Aaron Jackson, "'What About the Men? Investigating Alcohol Consumption, Masculinities, and Risky Sex in Peri-Urban Eswatini" (2019). Dissertations and Theses. Paper 5154.

https://doi.org/10.15760/etd.7030

This Thesis is brought to you for free and open access. It has been accepted for inclusion in Dissertations and Theses by an authorized administrator of PDXScholar. Please contact us if we can make this document more accessible: pdxscholar@pdx.edu. 
"What About the Men?"

Investigating Alcohol Consumption, Masculinities, and Risky Sex in

Peri-Urban Eswatini

by

Aaron Jackson Levine

A thesis submitted in partial fulfillment of the requirements for the degree of

Master of Science

in Sociology

Thesis Committee:

Maura Kelly, Chair

Daniel Jaffee

Lindsey Wilkinson

Louise Kaplan

Portland State University

2019 


\begin{abstract}
This study focuses on the narratives Swazi men create around drinking, masculinity, and sexual behavior. Alcohol myopia theory, motivational-expectation theory of drinking, and Connell's theory of masculinities were used to create research that details how alcohol and the cultural environment of gendered social drinking intertwine and interact with each other to form the gender structure of eSwatini. Twenty Swazi men were sampled by convenience, given semi-structured interviews, and questioned about their perceived and internal reasoning for the drinking of themselves and others, the observed drinking behaviors of others, their own drinking behaviors, how they viewed women in and accepted women into the gendered social drinking environment, and their own sexual behaviors while drinking or intoxicated. It was found that Swazi men drink as a performance of hegemonic masculinity and drinking is central to the masculine identities of the culture. Traditional and hyper masculine hegemonic masculinities as well as a number of subordinate and alternative masculinities are found in the narratives surrounding the gendered social drinking environment. An emphasized femininity is expected from women to avoid social drinking entirely while men gain a patriarchal dividend from women engaging in a pariah femininity through being present in the social drinking environment. The study concludes with recommendations for future research and international development efforts.
\end{abstract}




\section{Table of Contents}

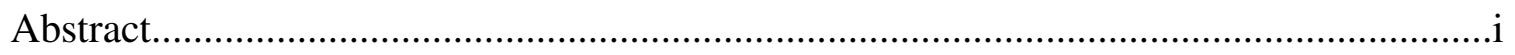

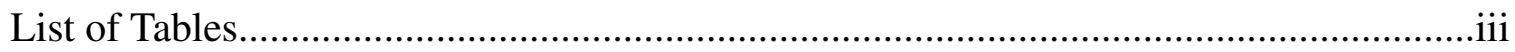

Chapter 1

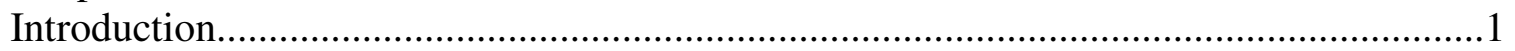

Chapter 2

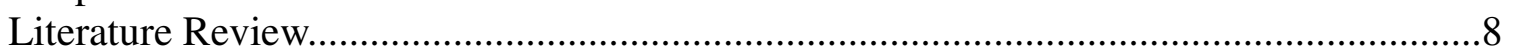

Chapter 3

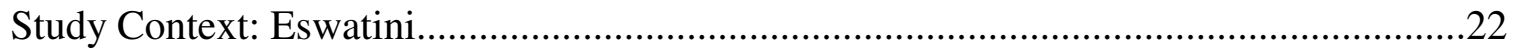

Chapter 4

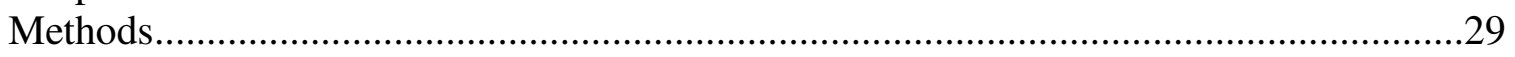

Chapter 5

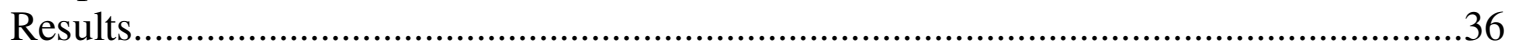

Chapter 6

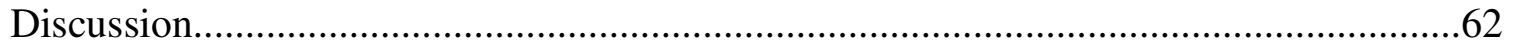

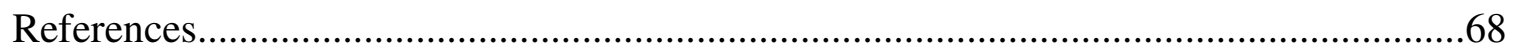

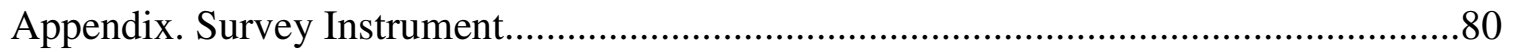




\section{List of Tables}

Table 1: Demographics of Respondents... 


\section{Chapter 1: Introduction}

Eswatini, the country formerly known as Swaziland, is a small land-locked subSaharan African country that shares borders with South Africa and Mozambique.

Scholars have primarily focused on eSwatini due to the country containing the highest prevalence per capita of HIV/AIDS infection in the world; $27 \%$ of all Swazi over the age of fifteen are afflicted with the virus, with an incidence rate of $1.4 \%$ increasing the number of those infected with HIV by around twenty thousand a year (CDC 2017). The highest rate of infection is attributed to risky sex (Lynne, 2006; Mahdi, 2015). Research has shown that alcohol consumption leads to risky sexual behavior (Labrie, et.al, 2002; Leigh and Stall, 1993), which leads to an increase in HIV transmission (Wen, et al., 2011; Zablotska, et al., 2007). Previous research has documented that eSwatini has a high rate of alcohol consumption (WHO, 2011; Morojele, 2015). Scholars have not yet examined Swazi masculinity, male drinking, and its possible implications for risky sex and HIV transmission. Thus, this research asks the question "how, where, and why do males in eSwatini between 18 and 35 drink alcohol, and does it affect their sexual behavior?"

What leads an individual to consume alcohol at all or in great quantities is still a contentious issue. Alcohol myopia theory argues that people become addicted to alcohol due to its ability to inhibit the person from focusing on the events of the past and possible consequences of their actions in the future, instead narrowing their focus to the environments and interactions of the immediate present (Steele \& Josephs, 1990). On the other hand, motivational-expectation theory posits that individuals consume alcohol because of an expectation of sensations being sought and how such expectations and 
sensations mix with their current environment (Cox et.al, 1988). Still another attempt to explain alcohol consumption is that past violent childhood trauma leads one to consume alcohol to deal with the stressors of the past (Hamburger, et al., 2008). While both alcohol myopia theory and motivational-expectation theory hold that there is an inherent, personal effect on the drinker during alcohol consumption that specifically influences behavior due to such consumption mixed with environmental cues, the trauma theory focuses more on how the self-medication of alcohol consumption exacerbates the negative behaviors of an individual suffering from past traumas. The key difference between the inherent effects of alcohol on an individual's behavior versus alcohol consumption and a change in behavior, such as an increased need for sensation seeking and a lack of focusing on the consequences of actions, is that the alcohol myopia and motivational-expectation theories argue alcohol consumption is the cause of certain behaviors while the childhood trauma theory and its supporting articles argue that people who consume alcohol are prone to act in a riskier manner anyway. One of the goals of this research is to determine which of the three theories is best at work in the Swazi male context.

When discussing the reasoning behind alcohol consumption all three theories agree that alcohol consumption has an inarguable effect on behavior (Goldman \& Roehrich, 1991). Whether alcohol consumption is the full cause or an accelerant of such behavior is the main point of contention between these theories, but such a change in behavior has been well documented. What has also been found is that alcohol consumption has a very strong effect on risky sexual behavior (Hendershot et.al., 2007). 
Risky sexual behaviors include taking multiple sexual partners (Cockcroft, et al., 2010), a large age discrepancy between sexual partners which adds a power dynamic to the relationship, and not using condoms (Dermen et.al, 1998). These risky sexual behaviors have also been known to accelerate the spread of HIV separately from other factors, such as unemployment and a changing social schema in regard to the gendered roles in the family. Such changes also increase alcohol consumption specifically from men (Krishnan, et al., 2009) possibly due to drinking being seen as a means for men to act emotionally while still maintaining their masculinity, as investigated in this research.

By focusing on male behavior, we must also address the larger topic of masculinity. Connell and Messerschmidt argue "Masculinity is not a fixed entity embedded in the body or personality traits of individuals. Masculinities are configurations of practices that are accomplished in social action and, therefore, can differ according to the gender relations in a particular social setting" (2005:836). Connell $(1987,2005)$ argues that cultures arrange themselves into an overarching gender order, now called the gender structure in contemporary scholarship (Risman and Davis, 2013), which aims to subordinate women to men. A hierarchy of masculinities forms and outlines this gender structure : hegemonic masculinity represents a configuration of behaviors and qualities that are exalted as the highest state of masculinity in a cultural or social context; subordinate masculinities represents a collection of qualities and behaviors that are given the least amount of power, status, and influence in a gender structure such as not engaging in socializing with peers, not playing sports, and avoiding conflict (Mayeza, 2017; Medich, et al., 2018); complicit masculinity is a configuration of 
masculinity that does not actively engage in the subordination of women but ultimately benefits from such subordination through the patriarchal dividend, benefits which all men receive in a gender structure that depends on the domination of women; and marginalized masculinity which explains how differences in social class, economic class, and ethnicity in men still allows the gender structure to hold up men as inherently superior to women despite the fact that such differences would lead to further stratification otherwise (Burchardt, 2017; Lynch and Clayton, 2016).

When discussing masculinity, drinking, and their effects on each other there is much evidence to suggest that drinking is a predominantly male behavior in sub-Saharan Africa. The greater context of sub-Saharan Africa in particular shows drinking to be seen as an inherently masculine and a predominantly male behavior (Malhorta \& Yang, 2010). Drinking as an expression of masculinity is correlated with engaging in risky behavior, attaining temporary or long term sexual partners in an effort to reclaim once attainable goals of masculinity now made difficult by unemployment, and other behaviors that run in parallel to behaviors seen as hegemonically masculine in the region (Tomsen, 1997; Vijay, 2018). Other qualitative investigations have looked at how brewing one's own liquor in sub-Saharan African countries affects drinking habits (Taylor, et al., 2016; Thakarar, et al., 2016), how narratives surrounding women as a measurement of masculinity affects sexual behavior in general and risky sexual behavior in particular (Hunter, 2005), and how sexual behavior is largely gendered, which can then be affected by the social context and exacerbated by alcohol consumption (Hatcher, et al., 2014). All of these factors are also present in eSwatini, which makes the social context and 
acceptance of drinking extremely important in explaining Swazi male sexual behavior in general and risky sexual behavior in particular.

eSwatini has a history of personal and familial brewing of alcohol, cultural ceremonies that have drinking and brewing at the center, and an informally recognized but institutionally under-reported problem with drunk driving and under-age drinking (UN Media IRIN, 2007). The national newspaper reports on drinking and driving offenses by naming the offenders in the articles (Mdluli, 2016), police raids have occurred to shut down possibly unlicensed alcohol sales (Shongwe, 2018), and yet there was only one reported case of alcohol addiction during 2016 (MEU, 2015). Self-reported evidence and the amount of drinking and sexual assault that happens at the three main cultural celebrations during the year, the Umhlanga, Incwala, and Buganu festivals, provides evidence to support the argument that the social/cultural environment of eSwatini supports drinking in male-dominated spaces, which allow males to engage in risky sexual behavior with relative social impunity (Times Editorial, 2018; 2013).

Most of the literature concerning eSwatini revolves around HIV prevalence and incidence, with the majority of that literature being focused on Swazi women and their social realities surrounding the infection and spread of HIV (Chipamaunga, et al., 2010; Simelane, 2011). International development based research and academic research has been examining this problem for decades, including quantitative and qualitative studies surrounding female HIV transmission (Mahdi, 2015), the stigma of contracting and living with HIV (Root, 2010), and how well Swazis are informed on sexual reproductive health (Lynne, 2006), but gaps exist in the literature regarding research focused on men, 
drinking, and male behavior surrounding drinking in Swaziland (Kalichman et.al, 2007).The majority of this literature is quantitative, either based on data gathered for the purpose of the study or secondary analysis of data gathered for other reasons (Buseh, 2004). A few studies focus on the narratives and themes surrounding the social lives and culture of eSwatini (Simelane, 2011; Root, 2009), with no research presently available that investigates the narratives of Swazi men and their place in Swazi culture. Alcohol consumption, as just a prevalent if not centrally important part of Swazi culture, is the primary focus of this research as a means of illustrating the narratives and processes surrounding the masculinities of eSwatini. With complementing previous research studies showing that males and male sexual behavior are the central components of risky sexual behavior (Feirman, 2012; Brear and Bessarab, 2012), this research hopes to weave a narrative around alcohol consumption, the masculinities of eSwatini, and risky sexual behavior to better understand why eSwatini has a disproportionate rate of HIV infection and alcohol consumption.

Drawing on Connell's $(1987,2005)$ theory of masculinities, this research provides evidence that drinking in eSwatini is central to the maintenance of the gender structure of eSwatini and also that such consumption has played a significant part in eSwatini's high HIV prevalence and incidence rate. While other research has shown that the subordination of women is a key component in the HIV transmission in eSwatini (Fielding-Miller et.al., 2016; Lynne, 2006; Mahdi, 2015; Root, 2010), I argue further that the gender structure of eSwatini, the masculinities and relations therein, and an analysis of the social drinking environment show how expressions of the hegemonic masculinity of Swazi 
culture have influenced the disproportionately high rate of HIV in eSwatini. 


\section{Chapter 2: Literature Review}

\section{Theories Regarding Alcohol Consumption}

The theories behind and personal reasons people give for drinking are highly varied. The most obvious reason research has discovered is that people drink when other people are doing it around them (Teunissen, et al., 2012). There has even been some research to suggest that people reason that the only means in which they can be social in large groups is when alcohol is involved (McCrady, 2004). The phenomenon of peer

pressure has been well documented in all sorts of other behaviors and the fact that people act based on a group identity is a central component of the discipline of sociology. There stands every reason to assume therefore that alcohol consumption, as a behavior, would be expressed more in individuals who had been around such practice more often than others.

However, the internal, biological, and therefore psychological effect alcohol has on the individual must be addressed when theorizing the reasons behind the existence and cultural universality of alcohol consumption. Motivational-expectation theory seeks to address these internal machinations by arguing that alcohol serves as a trigger for certain expectations a person has on their own behavior and the environment surrounding alcohol consumption (Cox et.al, 1988). When alcohol is consumed the expected outcome occurs, a somewhat unique experience in everyday cultural environments where expected actions do not always yield expected results. Research has also been done to examine whether or not drinkers are exceptionally fond of seeking out sensations, that there is a personal 
behavior one finds in those that consume alcohol (Hosier and Cox, 2011). Whether or not those that drink would engage in risky sexual behavior whether they were drinking, or not, is outside the scope of this paper, but alcohol triggers either an environmental or internal change in the behaviors of those drinking and has to be discussed when studying alcohol's obvious effect on behavior (Graham, et al., 1996).

Coming from a different perspective, the theory of alcohol myopia argues that the drinker focuses more on less salient and obvious social and physical cues in their environment instead of focusing on internal memories and thoughts regarding possibilities in their future while consuming alcohol (Goldman \& Roehrich, 1991). Alcohol myopia argues that such focusing on the present contributes to feelings of selfinflation, relief, and excess, with the latter influencing the individuals ability to consume more alcohol which can lead to addiction in some individuals. Feelings of relief are then closely associated with alcohol consumption and alcohol is then consumed for "stressrelief" and an increase of the enjoyment of already pleasurable situations. Alcohol myopia is different from the motivational-expectation theory in that what alcohol triggers is an entirely different brain state and not just the internal sensations an individual connects to drinking. While such triggers in the motivational-expectation theory can be altered due to the cultural environment and past experiences, which are also influenced by past cultural or social environments, alcohol myopia has a universal effect on individuals that then has a differing effect on behavior due to the cultural expectations, social environment, and past experiences of the individual. Both theories argue that risky behavior in general, but risky sexual behavior in particular, is affected by alcohol 
consumption and makes drinking an important part of understaning what affects risky sexual behavior.

As a final possible explanation behind the draw of alcohol consumption there have been a number of research articles focusing on the effect childhood trauma has on alcohol consumption. In a variety of cultures (Stickley, et al., 2013; Kiwanuka, et al., 2017), among twins (Sartor, et al., 2007), and even specifically among males who then engage in risky sexual behavior (Schraufnagel, et al., 2010) there seems to be a correlation if not a distinct causation between childhood trauma and whether or not an individual drinks alcohol. If childhood trauma were to fully explain alcohol consumption then the idea that alcohol has a distinct effect on risky general and sexual behaviors would be called into question; even if alcohol were only a trigger, the childhood trauma would be a better indication of risky sexual behavior than alcohol consumption by itself.

But the theories of alcohol myopia and motivational-expectation do account for the stress-relieving effects of alcohol; alcohol either makes the immediate social and physical environment the sole focus of the individual or the cultural and social themes surrounding alcohol consumption argue a supposed therapeutic affect, both allowing one to distance themselves from past childhood trauma. What further obscures the relationship childhood trauma has on alcohol consumption is that some studies have held that men and women respond to childhood trauma differently in regards to alcohol consumption (Slopen, et al., 2011), some have held that they respond to them the same (Sartor, et al., 2007), and finally some others have concluded that trauma has no effect on 
alcohol consumption whatsoever (Lien, et al., 2016). The Lien et al. study is most important to our purposes since it was conducted in South Sudan and concluded that drinkers in the historically war-torn region of Sudan consumed just as much alcohol as people in other African countries. What can best be concluded from this is that there might not be any quantity or quality of trauma that leads one to drink, but the possible therapeutic effects of drinking are a potential reason behind individual alcohol consumption.

In any case, we do know that alcohol has an effect on behavior. On one side we know that alcohol myopia contributes to risky behavior in general, but also a noted increase in sexual arousal in subjects that are drunk argues that such a change increases risky sexual behavior as well (Hendershot et.al., 2007). An increase in sexual behavior and risky sexual practices, such as not using condoms and having multiple sexual partners, has been noted in other research that measured the effect of alcohol consumption on sexual and non-sexual behaviors (Graham, et al., 1996). Investigating whether the alcohol myopia theory or the motivational-expectation theory is a better explanation for such a change in behavior based on internal biological changes or the expectations and motivations of individuals as focused through a cultural lens can aid in understanding how alcohol affects risky sexual behavior in eSwatini, if at all.

\section{The Theory of Masculinities}

Connell seeks to describe the affect of the gender structure, the subordination of women at the behest of men, in a culturally and historically flexible way (Connell, 1987). 
Connell's $(1987,2005)$ theory of masculinities argues that masculinity is a collection of behaviors and characteristics that individuals can practice in a multitude of ways that are then stratified into a greater gender structure. Masculinity represents an overarching pattern of behavior that is found in all areas of social life instead of one identity and one static set of behaviors and characteristics that all men strive for. These masculinities are created as a response to the subordination of women to gain the benefits of patriarchal dividends which are then unequally distributed among men who perform the qualities and behaviors that are considered masculine in that gender structure. . Connell's theory of masculinities also observes that hegemonic masculinity enforces a type of emphasized femininity ascribed to women as a representation of how best to be subordinate to hegemonic males.

Connell argues that cultures and societies are put into a gender order, a forced hierarchy that put men in dominance over women and which is now thought of as a gender structure (Risman and Davis, 2013). Such a gender structure of male dominance is commonly referred to as the patriarchy, an overarching social institution that dominates women for the benefit of men. This gender structure, found widespread in all cultures and societies, is comprised of all of the empirical arenas in which humans may interact such as the family, the homestead, the workplace, or in the case of this research, the practice of social drinking .

In the gender structure there are a number of ways in which men and women interact and relate to each other. Power relations deal with how men directly or indirectly 
subordinate women and maintain dominance (Connell, 1987). Such dominance can take many forms, symbolically or through direct force, and can be enacted by individuals or institutions. Production relations deal with how labor is gendered and how male labor is held in higher esteem and rewarded more than female labor because men are doing such labor, not because what male labor produces is more valuable (Connell, 1987). Emotional relations not only deal with how male emotions are held in higher esteem than female emotions but also in how the larger patterns of masculinity and gendered relations can be felt on a personal, anecdotal level that obscures the larger pattern of female subordination (Vijay, 2018). Emotional relations are a key component in how prejudice and misogyny are discussed, represented on the interpersonal level, and ultimately explained away as not being central to a larger pattern of female subordination. Finally, symbolic relations deal with how the subordination of women and dominance of men is communicated through speech, images, and actions (Pascoe and Bridges, 2016). These symbolic relations can come through not only in direct individual or institutional actions but also items and identities that represent other power, production, and emotional relations.

How masculinity operates within the gender structure as an identity or collection of qualities and behaviors divides the multiple masculinities into separate, but sometimes overlapping, groups of stratified behaviors and qualities found in that cultural and historical framework (Connell 1987; 2005). Hegemonic masculinity is the most easily identitfied example of masculinity in Connell's theory (Burchardt, 2018; Fielding-Miller et.al., 2016; Moosa and Bhana, 2018; Rich et.al., 2015): hegemonic masculinity represents a collection of qualities and behaviors that are the most culturally exalted in a 
gender structure. Such a masculinity has the highest claim to legitimate and direct violence in the efforts of the gender structure to subjugate women. Many studies talk solely of hegemonic masculinity, finding it useful in describing the international subordination of women through an idealized form of masculine action that men may take on and emulate at various times and in various contexts.

Hegemonic masculinity is not so easily defined without the existence of the subordinate masculinity in the gender structure: subordinate masculinity possesses the least respected or legitimized collection of behaviors and qualities in a society or given cultural context. Subordinate masculinity creates a clear stratification of hegemonic masculinity being greater than subordinate masculinity, which is still greater than female action and presence in the arenas of gendered relation.

A number of empirical studies have been conducted to better illustrate the presence of a gender structure and define the behaviors attached to hegemonic masculinity in the region of South Africa. From a very young age boys are acculturated to be aggressive, violent, and competitive (Bhana and Mayeza, 2016). The ways in which playground play and the self-policing of soccer work themselves out among unsupervised primary school children shows how early the ideals of hegemonic masculinity are upheld by young boys. Soccer is a claimed space that aggressive boys chase girls and subordinate, less confrontational boys away from (Bhana and Mayeza, 2016). Girls who want to play soccer are labeled as "tomboys", a negative stigma for a girl who is trying to be a boy, and when adults are brought in to deal with such labels they punish those 
labeling instead of addressing the idea that girls can act like boys and still remain girls (Mayeza, 2017). Boys can also be labeled "gay" as a means of enacting symbolic power to reinforce conformity to hegemonic masculinity (Bhana and Mayeza, 2016). Such a label has very little to do with any sort of sexual preference but labels a boy as wanting to be a girl, spending a lot of time around women in a platonic capacity, and not engaging in active physical violence at play time. That "gay" is a label of subordinate masculinity in the cultures of South Africa also comes out in how homosexual Zulu men faced with traditional circumcision were reluctant to call themselves gay (Lynch and Clayton, 2016); "gay" is a label with a separate connotation of behavior that has very little to do with sexual attraction and performance.

A majority of the studies dealing with masculinities in South Africa creates a dichotomy between two options of hegemonic masculinity: a traditional masculinity or a more modern hypermasculinity. Traditional masculinity focused more on gaining land, being responsible for one's land and family, and having a provider role (Gibbs, et.al., 2017). Traditional masculinity has the benefit of focusing on work, responsibility, and either only taking one wife or slowly accumulating wives, but adhering to such a culturally supported and sexually safe form of hegemonic masculinity has been difficult for young men to achieve in shifting economic realities, unemployment, and underemployment (Medich, et al., 2018; Hunter, 2005; Gibbs, et.al., 2017). In response, a hypermasculinity called in isiZulu "isoka", was created by younger men who could not achieve the more traditional, economic, and symbolically dominant hegemonic masculinity. The hypermasculinity of isoka relies on physical violence, conflict, fighting 
for space, and sexual promiscuity (Medich, et al., 2018; Gibbs, et.al., 2017). Such a hegemonic masculinity relies more on risky sexual behavior, and due to being created as a response to the inability to achieve a traditional masculinity, is not supported by other facets of South African culture which in turn make interventions to deal with such aggressive behaviors difficult (Medich, et al., 2018).

One major group resisting the strict dichotomy of traditional and hypermasculine hegemonic masculinities are university students (Vijay, 2018). While the respondents did report that they and their male peers were drawn, or pushed, into either a traditional or hypermasculinity, it was their romantic relationships that allowed them to portray a more nuanced form of masculinity. Being vulnerable with the women in their lives, looking to their relationships as centers of responsibility, and avoiding multiple partners and other facets of hypermasculinity not only draws upon the less dominant qualities of traditional masculinity but also is an effort to create a more acceptable modern masculinity (Vijay, 2018). However, within such performances of masculinity, homosexuality and thinking of their female partners as being equals was still not seen as acceptable.

Religion has been examined as a possible avenue for South African men to avoid the traditional masculinity-hypermasculinity dichotomy (Burchardt, 2017; 2018). While there is a possibility for men to enter a modern version of hegemonic masculinity that does not rely on aggression and sexuality, Burchardt found more often than not that the masculinity put forth by the Pentecostal Church tried to distance itself only from the religious and spiritual aspects of the local traditions and not from regional hegemonic masculinity. The alternative religious hegemonic masculinity of the Pentecostal Church 
that focuses on monogamy, responsibility, doing what is best for one's family, and hard work mimicked traditional masculinity in its focus on attaining a family and homestead while still not addressing the asymmetric power differences between men and women. In fact most of the physical and symbolic underpinnings of the church services, a central male authority speaking to a mixed congregation and supported by a small group of women, did more to support the dominance of men in the gender structure than it did to subvert the economic dominance of traditional masculinity (Burchardt, 2017). Such a distinction should be noted as a key feature of the overall gender structure of eSwatini as well, through the embodiment of the familial ideal in the King and his many queens (Kuper, 1961).

With a detailed description of how masculinities are performed and work on each other there must be an equivalent response from women and femininity. Connell (1987) describes an emphasized femininity that is formed around, and sometimes in response to, hegemonic masculinity. This emphasized femininity is the collection and configuration of qualities and behaviors that hegemonic masculinity finds most appealing in women in a given historical and cultural context. Emphasized femininity is a collection of qualities and behaviors that women are expected to practice in response to the perceived actions and inclinations of hegemonic masculinity (Connell, 1987). While women can and do behave in many different ways, each gender structure has a grouping of qualities for women that are performed in each gender hierarchy to best conform to hegemonic masculinity in those arenas. Such conformity to an emphasized femininity informs others of a woman's worth in the overarching gender structure : a woman is worth only as much 
as she is conforming to hegemonic masculinity.

Due to the passivity and lack of agency given to women in Connell's theory of masculinities, there has been some contention as to the extent of the gender structure. Schippers puts forth an alternative stratification of the hierarchy of masculinities and contends that there is a hegemonic femininity that is created in direct response to counter the domination of men (Schippers, 2007). Instead of taking gender as a performance only enacted by a single individual that embodies a position on the gender hierarchy, Schippers argues that these performances are ranked in relation to an ideal heterosexual relationship; there is not one set of dominant behaviors for men to adhere to for authority and one set of behaviors for women to adhere to for the benefit of such dominant behaviors, but instead all behaviors are put in relation to who is acting, how they are acting, and in what relation are they acting towards others. Schippers seeks to explain how dominant women and passive men, especially homosexual men who are acting in a culturally feminine way, fit into an overarching gender structure, and does not reduce men and women to masculinity and femininity (Schippers, 2007).

With women and men occupying the same gendered space instead of two separate gender hierarchies, Schippers also gives evidence of to how a hegemonic femininity is formed and works upon hegemonic masculinity. Schippers argues that how husbands and wives control each others' behavior is evidence of a hegemonic femininity; when wives in a working class neighborhood in Brazil gossip about their infidelity the wives do not face a stigma for such action but their husbands do (Schippers, 2007). If a wife is known to 
cheat on her husband, or even if she lets others know, then the husband is labeled as a cuckold and loses status, while the wife suffers no negative stigma. With married women being such a threat to the masculinity of married men, husbands are forced to physically and economically control the movements and behaviors of their wives. Such control is therefore folded into a dueling relationality of masculinity and femininity, with femininity being given a more equal share of power in the gender structure (Schippers, 2007). While Schippers does try to argue that there is also evidence of hegemonic femininity acting on women, and therefore embodying a full hegemonic femininity instead of an emphasized femininity that just conforms to hegemonic masculinity, the evidence of the second half of hegemonic femininity is not as well expressed due to a female hierarchy being formed along the lines of emphasized femininity (Schippers, 2007). However, the idea of a hegemonic femininity being formed to equally counter hegemonic masculinity is something to be contended with when using Connell's theory of masculinities.

Due to the economic realities facing women and men in eSwatini and the surrounding regions of South Africa, most masculinities research done in the area has not found much evidence of a hegemonic femininity nor a gender structure that is formed around the relational qualities between men and women. One study in eSwatini examined the narratives and behaviors surrounding emphasized femininity and transactional sex (Fielding-Miller et.al., 2016). The researchers were able to organize the four main relationships a Swazi woman can find herself in into a loose hierarchy of emphasized femininity, mainly based on the age and rurality of the woman. The marriage model of transactional sex involves older women in rural areas where the woman's 
husband is the sole provider for the family. The aspiring marriage model is typically held by younger women, possibly in more urban areas as well, who had their own finances but still accepted gifts and money from significant others as an expression of their partner's adoration. The university student model was held by mostly younger women who were seeking higher education and the more egalitarian romantic relationships and were culturally supported due to possible male partners also being able to earn more economically due to their education. Finally there was the least acceptable model of transactional sex, called the "Sugar Daddy" model which was formed by an older, and possibly married man, who was providing economically for a much younger woman or girl in exchange for sexual favors (Fielding-Miller et.al., 2016).

The researchers frame all four of these models of relationship as being forms of transactional sex: sexual favors are expected of the women in exchange for economic support. While such support is expected and received in varying degrees, there were no reported means for women to counter male dominance, and in all relationships women were expected to be demure and agreeable towards their male partners (Fielding-Miller et.al., 2016). Only in a few reported cases of women in "Sugar Daddy" relationships being told to leave by the wives of their male partner or the woman's own family is there any evidence of female ability to curtail male sharing of resources and dominance. In these instances the men face no sanction, and the women in marriage models and aspiring marriage models of transactional sex telling the women in the "Sugar Daddy" models of transactional sex to leave the relationship have no means of stopping their men from splitting their economic resources. The existence of the "Sugar Daddy" model represents 
a pariah femininity, female behavior going against the behavior dictated by hegemonic masculinity (Schippers, 2007). The economic stranglehold men have that leads to their overall dominance of women in the gender structure of eSwatini is not countered by any covert or overt hegemonic femininity. 


\section{Chapter 3: Study Context: Eswatini}

\section{Eswatini and Drinking Culture}

eSwatini is in a unique political and physical environment that has affected the cultural and economic environment in regards to drinking in particular (Gillis, 1999). eSwatini was a protectorate of Britain during the time of European colonization of Africa, and the Kingdoms of eSwatini and Lesotho are proud holdouts against what other countries have seen as the divisive actions of colonizing powers. The maintenance, control, and protection of Swazi lands, cultural practices, and economy has solidified the culture of eSwatini to become a defensive and stalwart monoculture that focuses on traditional cultural practices as being the only means of acceptable cultural expression (Kuper, 1961). These traditional means of cultural expression can also be seen in men focusing on taking on multiple sexual partners instead of being able to attain and provide for the multiple wives that represents the economic and cultural goals of men in eSwatini and Kwa-Zulu Natal (Hunter, 2005).

There are a number of specific cultural events that directly influence the drinking culture of eSwatini. The cultural events are held yearly and involve either overt indications for drinking, in excess or otherwise, or hold covert indicators towards drinking and gendered power dynamics. The two cultural events that have a covert focus on drinking paired with a focus on gender and power are the female Umhlanga festival, or Reed Dance, and the male Incwala Ceremony. Umhlanga is a festival where women and girls who are unmarried and have not had children, traditionally considered "virgins", 
march to one part of the country to cut a number of tall river weeds and then ceremonially present them to the queen mother to reinforce a fence found at one of the main royal residences to reinforce a permanent wall there, an important cultural reflection of the country supporting the authority and protection granted the royal family and symbolically and physically reinforcing their permanence in the area (Kuper, 1952). The women and girls perform traditional songs and dances while walking by the queen mother then the king of eSwatini in turn. The women and girls are topless and wearing very little clothing below the waist in a show of fertility and virginity. The king also picks a new wife from the parading girls, symbolizing that any Swazi girl would have to obey the summons of her king King Mswati III, but such marriages are prearranged well in advance to reinforce political alliances. During the week-long camp out where young women sleep out in the open they are guarded by men of either cultural or political distinction, representing symbolic and political control over the young women, where various reports of excessive drinking and sexual assault have occurred (Times Editorial, 2013). The male focused Incwala deals with the ritualistic invigoration of the king's cultural and spiritual authority in the country (Kuper, 1952). Much like in Umhlanga, men cut a spiky branch and bring it to reinforce the king's kraal, or cow corral, as a cultural and physical reinforcement of the king's physical and spiritual authority due to the kraal symbolizing the center of a Swazi family's spiritual and economic strength. The event deals with shows of strength, ritualistic spiritual cleansing specifically hidden from the public, and the peripheral consumption of alcohol that happens with most social gatherings in eSwatini. 
The most overt focus on drinking and brewing is found in the Marula festival which deals with the harvesting, brewing, and consumption of buganu, an alcoholic drink that is made from the marula fruit (Matsebula, 2002). The marula is a small, plum like fruit that grows during December-January and is harvested en masse and brewed for a month or two. The actual festival happens in February and multiple parts of the country host official marula festivals, while other parts host unofficial or smaller marula brewing and drinking festivals. Public intoxication, drunk driving, and sexual assaults rise dramatically during the time period marula is brewed and consumed. Buganu is a seasonal drink and is paired with narratives of excessive drinking along with a cultural mythos that states that if a man drinks too much buganu his sexual and physical appetites will be uncontrollable and he will not be in full control of his actions. A number of rapes and sexual assaults have been blamed on buganu causing men to act excessively, but no such narratives surrounding female excessive appetites have been mentioned (Matsebula, 2002).

Umcombotsi is the traditional alcoholic beverage that is brewed year round (Simatende et.al, 2015). Umcombotsi is brewed from fermented sorghum and is only available in private homesteads or at cultural bars called "shabeens" that produce and sell their own umcombotsi. The drink has a low alcohol and high caloric content, which paired with its inexpensive production, allows umcombotsi drinkers to consume the drink the all day long at a social location without facing the negative effects usually found with excessive drinking. Umcombotsi is also commonly thought to produce some invigorating properties, so it is produced as an incentive for continuing the work of the large scale 
harvesting of corn that occurs twice yearly. The drink is also provided at all night vigils that commonly occur on Saturday night into Sunday morning that constitute a main part of Swazi traditional funeral services (Magagula, 2013). Umcombotsi is culturally brewed by women, with the decision to brew being on the male head of the household for the sake of finishing the harvesting of cash crops.

The cultural environment of the tavern, bottle store, or bar is seen as an especially male dominated area (Rich et.al., 2015). Men in South African bars attempted to consume as much alcohol as their friends in an effort to perform dominance among their social group. Men also blamed female sexual partners for not adhering to safe sex practices even though female tavern goers reported that men were most often the ones to control contraceptive use. Men sexually objectified women through various means such as false declarations of love in exchange for sexual favors and transactional sex being demanded of men after purchasing food and drink for women that were not informed of such an agreement beforehand. The study also focuses on how male behavior leads to more far reaching consequences for women through sexism and violence by men which can include anything from police being unsympathetic towards rape victims to men intentionally praying on intoxicated women (Rich et.al., 2015). Due to the physical and cultural proximity of eSwatini to South Africa it can be expected that such events also occur in the cultural environment of Swazi drinking spaces.

These events and factors of the cultural environment are by themselves not detrimental to health nor increase the prevalence and incidence of HIV, but when paired 
with the theory of masculinities that influences how men and women navigate power, production, emotional, and symbolic relationships, the convergence of these factors reveals how male alcohol consumption can lead to an increase in HIV transmission due to risky sex (Weiser et.al, 2007).

\section{Eswatini and Marijuana}

In addition to alcohol, eSwatini has a strong cultural and economic connection to marijuana, called "dagga" colloquially. Dagga is seen as a culturally traditional intoxicant (Motsa, 2016) with a complicated relationship to modern eSwatini. Due to the plant being easy to grow and producing dramatic effects much like umcombotsi and buganu, dagga has been used by Swazi recreationally for generations (Motsa, 2016). The effects of dagga are so desired by Swazis that some homesteads and impoverished families rely on the production and sale of dagga to supplement subsistence farming and unskilled labor commonly called "piece jobs" (Polgreen, 2012). Because of the high prevalence of HIV and a lack of access to necessary medications in poor rural areas, $0.6 \%$ of the population dies to HIV every year (WHO, 2011), leaving the oldest generation in charge of raising the newest (Polgreen, 2012). Such a dramatic need for increased income has forced many single parent families to turn to the production and sale of dagga to support large extended families (Polgreen, 2012).

How eSwatini should deal with the economic and cultural need for dagga has been up for debate for a decade or two. While dagga is currently illegal in the country, the cultural and economic need for its production has lead to many complications between 
the traditional, impoverished, and rural areas versus the globalizing, industrializing, and urban areas of the country (Motsa, 2016). Because of the cultural support for and plentiful supply of the drug, most public drinking establishments support or at least ignore the use of dagga while consuming alcohol, if not sell the product under the table themselves (Rich et.al., 2015).

\section{Eswatini and HIV}

The specific cultural and economic factors that influence the social environment of drinking and masculinity in eSwatini play an important role in the male, and therefore also female, prevalence and incidence of HIV. The highest HIV prevalence in females occurs in the 14-24 year old range and is due to the economic situation of young women and girls in eSwatini that supports older males with HIV having economic and sexual control over women as their "blessers" and allows the sexual attentions of younger women on older and more economically powerful males to provide for their families (Zamberia, et.al, 2009). Once these infected women are older, then men ages 18-35 start getting sexually and socially involved with them, which can be seen in the increased prevalence and incidence of HIV in that age range of males.

Research has been done on what environmental conditions and individual actions contribute to the increased prevalence and incidence of HIV. These factors, commonly called risky sexual behavior, include but are not limited to age differences between sexual partners, multiple sexual partners, alcohol consumption, violence, and a lack of use of sexual protection, namely condoms. While violence and sexual protection have been 
studied in eSwatini (Breiding, et al., 2011), there has been a lack of research on the other factors contributing to risky sexual behavior. A large age difference between sexual partners brings with it a difference in power, either directly through respect and status or covertly through a difference in economic power between partners (Daly, 2001). Multiple sex partners also increase the chance of transmitting and becoming infected with HIV due to incorrectly using sexual protection, exacerbated by a small and repeatedly reinfecting circle of sexual partners (Ziyane and Ehlers, 2007). Other studies have also shown that drinking contributes to increased HIV contraction and transmission due to either a decrease in inhibitions focusing on future consequences (MacDonald, et al., 2000), looking for greater sensation seeking (Goldman and Roehrich, 1991), and/or a created narrative around alcohol consumption and sex that one cannot be expected to use a condom when drunk and sexually hungry (Orubuloye, et al., 1997). These last three possible contributing factors have not been researched in eSwatini and are a key factor in what we know contributes to risky sexual behavior and the prevalence and incidence of HIV. That drinking is largely a male endorsed activity in eSwatini is a possible reason for the lack of research, either due to access, focus, or funding, but drinking is too central to the behaviors of multiple sexual partners, power differences between partners, and of course sexual intercourse while drinking or drunk to not be examined as a possible cause of the high incidence and prevalence of HIV in eSwatini. 


\section{Chapter 4: Method}

\section{Data Collection}

Data was collected through twenty semi-structured interviews, conducted with the aid of a translator. The translator, a local social worker, was also used to identity likely candidates for the interviews. I interviewed twenty Swazi men between the ages of 18 and 35 in the peri-urban Lobamba Lomdzala. (Ministry of Health, 2017). The table below (Table 1) details the family, employment, and home ownership statuses of each of the respondents. The majority of respondents were periodically employed with six having steady reliable employment, a few being employed seasonally by the local cannery, and the rest earning small amounts of money with light manual labor and maintenance that are called "piece jobs" colloquially. A few had completed high school but the majority of respondents had only finished the primary education that had been made free by the government a decade or so ago. Most of the respondents had some high school education but did not finish, with some reporting that the fees associated with high school education were too high for them to continue. An important distinction of class within this sample however is that only two respondents owned their home with the majority renting and some living with family already in the area. Owning a home is seen in the region as a precursor to being able to start a family and find a way into a more traditional hegemonic masculinity (Gibbs, et.al., 2017). 


\begin{tabular}{|l|l|l|l|l|}
\hline Name & $\begin{array}{l}\text { \# of } \\
\text { Children }\end{array}$ & $\begin{array}{l}\text { Marital } \\
\text { Status }\end{array}$ & Employment Status & Home Ownership Status \\
\hline Alan & 1 & Single & Piece Jobs & Renting w/son \\
\hline Brent & 1 & Girlfriend & Seasonal Work with Piece Jobs & Renting Alone \\
\hline Carl & 1 & Single & Mechanic & Renting Alone \\
\hline David & 2 & Girlfriend & Construction & Renting with Family \\
\hline Edward & 3 & Married & Seasonal Work & Owning with Family \\
\hline Fred & 3 & Single & Part-Time Construction & Renting with Children \\
\hline Greg & 1 & Married & Civil Servant & Renting Alone \\
\hline Harry & 0 & Single & Piece Jobs & Staying with Family \\
\hline Kurt & 0 & Single & Seasonal Work with Piece Jobs & Renting Alone \\
\hline Joseph & 0 & Single & Mechanic & Renting Alone \\
\hline Lewis & 2 & Single & Piece Jobs & Renting Alone \\
\hline Michael & 3 & Married & Hocker/Independent Retailer & Owns with Family \\
\hline Nathan & 3 & Single & Piece Jobs & $\begin{array}{l}\text { Lives with Family with One } \\
\text { Child }\end{array}$ \\
\hline Oscar & 2 & Single & Piece Jobs & $\begin{array}{l}\text { Lives with Family with } \\
\text { Children }\end{array}$ \\
\hline Patrick & 0 & Single & Piece Jobs & Lives with Family Alone \\
\hline Quentin & 0 & Single & Piece Jobs & Lives with Family Alone \\
\hline Richard & 0 & Single & Bricklayer & Lives with Family Alone \\
\hline Sam & 1 & Single & Piece Jobs & Lives with Family with Child \\
\hline Timothy & 3 & Girlfriend & Carpenter & Rents Alone \\
\hline Victor & 1 & Single & Unemployed & Lives with Family Alone \\
\hline
\end{tabular}

Table 1: Demographics of Respondents

It should be noted how the peri-urban area of the Lobamba Lomdzala region is different from the rural area of eSwatini and the urban areas surrounding the larger cities such as Manzini and Mbabane. Rural areas have very little economy and still rely heavily on subsistence farming, but have enough space to allow men to strive for a traditional masculinity based on homestead and family ownership. In the urban areas found near the center of eSwatini there is much less space for traditional homestead ownership, but the economic opportunities are greater if an individual has graduated high school. The per- 
urban areas of eSwatini make up the difference between these two economic and cultural extremes: peri-urban areas may have one or two main industries such as sugar cane farming, fruit that is grown seasonally and canned, or textile mills while still having an amount of space for high income individuals to ask for land from the local traditional authority to build a house on. Because of the hybrid nature of the peri-urban area there is a large difference in class between those respondents who do not own a home and those that do: only one respondent that was married did not own his home, showing a clear distinction that home ownership is an economic symbol for the personal ability to start a family, which is a central component of traditional masculinity in the region.

Class distinctions would have been much different if respondents would have been taken from the urban area, as opposed to not being much different if rural respondents would have been interviewed. The higher population density mixed with the higher earning potential has changed the landscape on class distinctions in the urban areas of eSwatini, and while such distinctions are outside the purview of this research such a distinction should still be noted as not being contained within interviewing respondents from a peri-urban area. While the same limitation in scope could be said with rural respondents not being represented in this sample, the small difference in population density but large difference in economic earning potential would have produced a smaller shift towards more traditional ideas of class and masculinity than if urban respondents had been interviewed. Traditional masculinity is called as such due to it being centered on ideals grown in the rural areas of the country and region, with only decreasing economic opportunities shifting ideas of masculinity in the rural areas, and not a lack of space or 
land to own a homestead and therefore signal the beginning of creating a family.

Interviews were between thirty minutes to an hour depending on the topics discussed and the amount of translating needed. The translator, Nosipho, had lived in the area for a number of years and was very comfortable gathering respondents, either through reaching out beforehand or bringing them in off the street before the interview. Interviews were held Tuesday, Wednesday, or Thursday to avoid the possibility of respondents being intoxicated during the interview. The interviews were held in a small hut attached to the homestead Nosipho lived at and were recorded on a cellphone in the center of the room. Notes were taken during the interview to note the economic status and age of the respondents, as well as some other information that was asked of Nosipho to clarify an interaction. Respondents were given a small amount of money (100 rand, or \$7) as an incentive that was given after the end of the interview. A consent form was given, written in English, but normally translated for the respondent into siSwati by Nosipho, that stated the incentive would be given at any time if the respondent did not wish to continue the interview further.

Nosipho was the principal agent in gathering respondents. Having lived in the area for sometime, studying to be a social worker, and having been used for other qualitative work by other non-governmental organizations in the area she was able to gather the twenty necessary respondents after I explained who I wanted to interview and why. Nosipho sampled exclusively conveniently and while she did specifically plan out a number of respondents to interview there were enough men lounging in the surrounding 
homesteads and shops in the area that she was able to furnish me with two to three interviews per day over the course of seven to eight weeks. No other sampling strategy was employed outside of who Nosipho could find and who was willing to speak to us.

As the interviewer, my gender, ethnicity, and height must also be brought up when discussing the method of data collection. As a white male who is relatively tall, most Swazis give a lot of authority and respect to me in the form of behavior and word choice. In the interview setting, it could be said that I may have passively and unintentionally either influence certain answers from respondents or quelled attempts at ending the interview prematurely. At the time the interviews had been conducted I had been living in eSwatini for two and half years and had been working in the specific area of the respondents for six months. Due to my familiarity with Swazi culture and how my positionality plays out in my interpersonal interactions with Swazis of all ages and genders my presence may have also induced answers that would not have been chosen if I were someone else. To address these limitations I kept my tone of voice and word choice informal, made jokes whenever possible, and gave my full and focused attention when my questions were answered. I hoped such intentional communication eliminated my ascribed authoritative status as a white male and prevented respondents from giving me answers they thought I would want to hear.

As my translator, Nosipho may have also influenced the answers of the respondents. However, due to her being a social worker, having interviewing experience, and admitting to me that she was surprised at the veracity and candor of the answers 
given, I find it safe to say that her presence did not influence the interviews very much. My own familiarity with Swazi men and Swazi culture also led me to believe that her presence as a translator, a third party to what was being said, and being female did not affect the responses noticeably compared to my private informal interactions with people who were demographically similar to the respondents. While it could be argued that when the topics of interacting with or opinions towards women would possibly be influenced by the presence of a Swazi woman the answers given by respondents, translated or in English, were just as critical and honest as those found in my informal interactions in Swazi culture. So while the presence of Nosipho may have influenced the respondents, I detected no such dramatic change that would lead me to believe I was getting false answers in the interviews.

Data Analysis

All data were fully transcribed from written notes and audio recordings and inputted into the qualitative data analysis program Dedoose. The interviews were open coded for responses having to do with the reasoning behind alcohol consumption, environments and timing of alcohol consumption, cultural events and ceremonies that have drinking associated with them, gender in relation to the expectations and stigmas behind drinking, and the actions taken during and after drinking alcohol. The respondents were given English pseudonyms so as to not distract the reader with siSwati names. Most, if not all, Swazis are given an English secondary first name or middle name so the use of English pseudonyms is not culturally erasing. 
An inductive approach to data collection was used to fulfill the parameters of the broad research question. During the analysis phase a number of theories were identified and used to explain the data. Themes regarding masculinity, the expectations men had for female behavior, and the centrality of the social drinking space in male behavior as a public space expected to be exclusively populated by males and as a reflection of the expectation of the existence of women and children to be largely populating the homestead emerged in the inductive coding of the data. After this analysis, I went back to the literature surrounding masculinity theories and empirical research focusing on men and male behavior in the region. Due to the data being found to parallel so many other empirical studies, and some of those studies using Connell's theory of masculinities, mapping the theory of masculinities to the data gathered from these interviews proved extremely effective. Much of the data gathered from this research regarding gendered spaces, masculinity being expressed through a variety of actions and inaction towards various social phenomena, and the theories behind the existence of one or more masculinities added to the validity of this analytic approach and the conclusions made therein. 


\section{Chapter 5: Results}

Over the course of these interviews I reached a saturation point of data that pointed at some very strong narratives regarding how, when, and why Swazi men drink. These narratives of the gendered social drinking environment, namely how multiple masculinities operate within this particular gender arena, coalesced into a representation of the larger gender structure at work in Swazi culture (Brear et. al., 2012; Breiding et. al., 2011; Daly, 2001; Fielding-Miller et.al., 2016; Feirman, 2012). Gendered drinking practices, as event, space, and behavior, reveals the larger gender structure of Swazi culture that articulates what masculinities are in place, how men and women interact within the gender structure, and ultimately how the domination of women exacerbates the spread of HIV in eSwatini. While this investigation started by seeking to articulate the narratives of and behaviors associated with Swazi male drinking habits, by its conclusion this study uncovered a greater picture of not only how drinking illuminates the gender structure of Swazi culture but also how drinking is a central component of Swazi masculinities.

To better show how drinking is central to the masculinities of eSwatini, I will first show how hegemonic masculinity and social drinking both activate and illuminate each other and how drinking is a central theme of Swazi masculinity. To better support the existence of a distinct hegemonic masculinity in the gendered social drinking environment I will also show the existence of other subordinate masculinities in the social drinking environment and the varied ways socializing, drinking, and sexuality are practiced in combination to perform different masculinities and create a stratification of 
masculinities in the social drinking environment that is also reflected in the greater gender structure. Finally, as a means of further illustrating how Swazi male drinking habits affect risky sexual behavior, I will show how talking about drinking with and around Swazi women articulates the double standards in the social drinking environment and the emphasized femininity of Swazi women as expected by Swazi men in general and the hegemonic masculinity of eSwatini in particular.

Hegemonic Masculinity and Social Drinking

Respondents discussed what they enjoyed most about being a man in their culture, and most of their ideals could be found reflected in the expression of hegemonic masculinity in the social drinking environment:

[What I like most about being a Swazi man is that]* I am able to have a farm, I'm able to have a homestead, and land. I am able to sustain myself. (Greg)

I'm able to take as many wives as possible in the Swazi custom and law. But unlike [a Christian] wedding, where you are only bound to one partner...[in a traditional Swazi marriage] as long as I'm able to take care of those wives I can take many wives.... [It just depends on] the money that you have, the income that you have that determines how many wives you can have, that you can take care of. (Henry)

Being the head of the household and being the most responsible person (is what I like most about being a Swazi man.) (Oscar)

I have the last say in any decision. And I am the most critical part of the society if I am a male. (Alan)

*Sections in [ ]'s have been reworded for clarity, while sections in ( )'s have been condensed due to English being the respondent's second language.

Control, independence, critical decision making, and polygamy are all idolized in Swazi masculinity. That hegemonic masculinity in the gendered social drinking environment reflects these key factors in the idealized Swazi man: the hegemonic male in 
the drinking environment is expansive, social, sometimes violent, safely emotional, and able to engage with new sexual partners outside of his more formal relationship(s). These behaviors and actions are necessary components of the control, independence, critical decision making, and polygamy characteristic of the idealized Swazi man and the traditional hegemonic masculinity of eSwatini.

In eSwatini drinking is a very social event. It is usually done solely by men at the bars, bottle shops, and more traditional shabeens instead of the homesteads and private dwellings. Bars have games, a television playing with a football game on, and are frequented by almost every male in walking distance from the bar. Drinking is done on weekends, the entire weekend, from Friday to Sunday depending on individual preference. A typical respondent of this study will start drinking after work on Friday, wake up and start drinking on Saturday, and possibly do the same thing on Sunday and only stop drinking early Monday. Respondents were explicit in describing that they drank on Friday, Saturday, and sometimes Sunday; my own observations of Swazi males in the area confirmed the specific days the respondents said they usually drink while also filling in the assumed realities surrounding when they started and when they stopped drinking during the weekend.

Most respondents reported that the only real factor that limited their drinking at any one time was how much money they had, only stopping their drinking once they had run out of funds. Respondents explicitly stated that a lack of funds was their most common reason for not drinking further, with some respondents saying the late hour or fatigue would bring them home from the bars and bottle shops. From my own 
observations I can confirm that drinking through the night and into the morning of the next day is not uncommon, which lends credence to the idea that only a lack of funds stops most of the male social drinkers of eSwatini. This general overview of the drinking habits of Swazi males is useful in outlining how masculinities are at work in the bars and bottle shops of eSwatini and mimics such behavior found in other drinking areas in other countries in the region (Rich et.al., 2015).

Hegemonic masculinity is displayed in drinking environments through drinking through the night, being possessive of or otherwise directly interacting with the women drinking around oneself, making sure to engage sexually with a women before the night is through, being sociable and outgoing, and buying as many rounds of drinks as one can afford or has friends to give drinks to. Hegemonic masculinity also involves not being accepting of the misbehavior of people drinking but possibly also engaging in violence and crime oneself due to the drinking environment, taking advantage of people in a lowered state of consciousness, or as a means of rebelling against a changing and stressful world.

Further illustrating the importance of drinking to hegemonic masculinity, one respondent, Victor, even goes so far as to say that drinking is a natural and inevitable experience for men:

I don't know about other people, but I drink because there are problems that come up in life, things that you need to do earlier before it is late. (By this I mean you) may find a married man (who) has never drunk in all his life. (By the time he is 42) you find that he may have a misunderstanding with his wife and the first thing he is going to think about is to drug himself. He is going to go back to alcohol. That person is already old, those are the people that tend to be manipulated at the bars because they do not know how the life (is at the bars). If 
you do it now, when you are young, I feel that it is better. Because even if I married a few years later when I come across a problem I do not think of alcohol, even if I had bought it before I know about the consequences and challenges of using it. (Victor)

Victor does not think there is an alternative to drinking to help ease personal trauma. Drinking is seen by Swazi drinkers as being the main means by which to handle emotional problems; it is the inevitable first choice for Swazi men to cope with life. It is the idea of drinking as a coping mechanism, either to accentuate enjoyment or suppress stress, that is an expression in class differences between rural, peri-urban, and urban areas in eSwatini. Victor's ideas surrounding the personal importance of drinking stem from the traditional, rural roots of Swazi culture, in that drinking is sometimes the sole means for rural men to talk openly and plainly about personal and social problems they may be facing. Due to the economic and physical ease of brewing the more common traditional brew of umcombotsi, drinking is sometimes the only means of recreation for men in rural areas. If drinking is not the only means of recreation for rural, and therefore impoverished men, then it is certainly the only means in which rural men can be emotionally open and vulnerable with other men to discuss important issues.

Most narratives surrounding the reasoning behind people drinking in general, and men drinking in particular, dealt with either the stress relieving effects of drinking or the increase in personal enjoyment that occurs when drinking. This stress relief deals with deficiencies in other gender relations, but the aspect of enjoyment also deals with how hegemonic masculinity in a drinking environment is expected to be consuming alcohol as a means of being increasingly social. All of these facets of behavior, the assertiveness, the 
aggression, the forthright sexuality, all conform to other ideals of hegemonic masculinity performed in other countries in the region (Medich, et al., 2018; Mayeza, 2017; Bhana and Mayeza, 2016; Lynch and Clayton, 2016).

One respondent, Michael, represents an idealized version of Swazi hegemonic masculinity. Michael is married, has his own homestead, a steady job, and three children. He is the actual and symbolic head of his household, a status created from and conforming to the actual and symbolic control of the King in accordance to the people of eSwatini. Michael explains the process of his drinking during the weekends:

We normally purchase alcohol in town then bring it to my homestead to drink it. I drink with my friends and brothers. My family normally has a time limit on what time I must stop drinking alcohol, and normally they bring in food that I can eat while we drink, and they actually tell me when it is time for my friends to leave when the others I invite over start misbehaving (my family tries to kick them out). (I approve or disapprove of that depending) on how happy I am with my friends. Like if I am happy with them I want them to stay longer...sometimes my family will tell me that my friends are not good to be around us, and sometimes we move away from my family and sit somewhere else and go drinking there...It depends on where you are (when you are drinking). Sometimes you are welcome, sometimes you are not welcome.

Michael doesn't even start his weekend where everyone else is: buying alcohol at the public drinking spot. He has a car so he can buy alcohol in bulk for his friends. How and where he ends his drinking shows his hegemonic dominance over his family in such a way that no other respondent can show. Because of his economic and symbolic dominance over his family he is able to invite friends over to his homestead, feed them, and then negotiate a time with his family for them to leave. Michael does not mention much how he may be affecting his children with his behavior, another facet of hegemonic masculinity being an avoidance of child rearing (Moosa and Bhana, 2018). While it isn't 
known how Michael's friends specifically act while drinking around his family, there are narratives surrounding how hegemonic masculinity is practiced in social drinking environments:

(People misbehave) normally (by not giving) way to people that are passing by... (People these days misbehave while drinking) by acting like they are on top of the world...60\% of the Swazis are still respecting the Swazi traditional norms. But the other $40 \%$ are now behaving like the South Africans (while drinking)...they act violently while they are out drinking. (Micheal)

You find yourself displaced because you are drinking alcohol, sometimes will drinking alcohol you find yourself in an entirely different town. So sometimes people snatch other people's wives, or sometimes they fight, there are so many things that can happen. (Timothy)

Some misbehave when they are drunk. Like picking on you, and making me feel small when I'm not drunk. (Patrick)

Hegemonic masculinity in the social drinking environment of eSwatini is

commonly loud, aggressive, socially and physically assertive, and sometimes dangerous.

Most social interaction in Swazi culture is focused on almost extreme levels of conflict avoidance, according to my own observations, so for some men to become more socially assertive or conflict oriented while drinking can be seen as an aggressive change in behavior. That Michael makes a distinction between how Swazis act versus how South Africans act is not uncommon: making the distinction between "acceptable" and "unacceptable" behavior along ethnic/national lines between Swazi behavior and the behavior of those from South Africa. While a number of respondents talked about the abstract concepts of respect and traditional behavior, none of the respondents were able to empirically define the actions and behaviors of such concepts. From the context of the conversation and my time in country, the Swazi traditional norms Michael is speaking 
about center around conflict avoidance and focus on age differences in power dynamics found elsewhere in the culture. That Michael talks about traditional norms being countered by the hypermasculinity now found in the social drinking areas of eSwatini is an important distinction between traditional and the now emerging hypermasculinity found in the region (Medich, et al., 2018; Gibbs, et.al., 2017). The behavior Michael does not like to see is also consistent with the conflict-oriented and physical domination of space found in other displays of hegemonic masculinity in the region (Bhana and Mayeza, 2016; Mayeza, 2017; Medich, et al., 2018).

Some respondents more explicitly illustrate and represent the hegemonic male who is loud, violent, and drinks to act as such:

When I'm drinking I have so many powers. If I'm drunk I get a lot of power, and I'm brave enough to go and do anything when I'm drunk. But when I am sober I wouldn't go and do that. When I'm drunk I don't even fear the police....I feel free, because I go shouting whatever I want to shout, and I feel free about it knowing no one is going to hurt me....(When I am drunk) I go around shouting and offending people....I have been in many fights....(When someone else is drinking) if he makes noise, and makes trouble, we beat him or her up. (David)

David represents the dominant, modern version of hegemonic masculinity found in gender social drinking as well as other facets of the gender structure: the collection of qualities that are given the highest status and power when economic attainment, family size, and land ownership are not available. While drinking David can be loud, sexual, social, and even violent due to his focusing on the hypermasculinity emerging in the region. How the other Swazi men, and also David, discuss these occurrences not only shows that this is what men do in such drinking environments but also what they are allowed to do. Only David talked about stopping men from acting in such a way and he 
himself acts in such away, enacting a personal double standard around the hegemonic masculine identity in such an environment. Other respondents only reported that men may misbehave and they were quick to report things they did not like happening around them, but no others talked about the possibility of controlling or acting against such misbehavior. It is because this outward, energetic behavior in a drinking environment is indicative of the qualities associated with hegemonic masculinity in a gendered social drinking environment that it is allowed to occur despite personal convictions of the respondents to the contrary. Such Swazi hegemonic masculinity reflects the "isoka" hypermasculinity as portrayed by the men in neighboring kwa-Zulu Natal (Vijay, 2018; Gibbs, et.al., 2017).

The emotional relations in drinking environments are sorted into two broad categories. The first category of emotional relations in the gender social drinking environment involves how male emotional behavior is dealt with while drinking. Unlike how negative male behavior is noticed and usually avoided by men in the social drinking environment, alcohol consumption is recognized as being useful in allowing Swazi men to emote while drinking. Respondents consistently talked about how drinking was key component of getting into important discussions with other men, as Michael details:

We socialize, we talk about the reality of things when we drink alcohol...In drinking alcohol some men bring some certain disrespect on the family's because they misbehave sometimes, sometimes they talk certain things that they should not be, or not respecting the wife that he has...Like some people they are not able to confide (in others) when they are sober. So once that person is drunk they are able to talk about whatever problem they have. So we discuss the whole problem and help advise them on what to do in their particular situation. (Michael)

While these important and emotional discussions could happen while sober, and 
potentially with the people who are involved more directly in the conflict, there is an emotional weight behind alcohol consumption that is supported by the idea that being emotional is more acceptable while intoxicated. The idea that there is a barrier between men and their emotions at other times and with other people makes the public drinking spot a therapeutic and special place that is unique due to the emotional silencing of men in general with the dominance of the hegemonic masculine stereotype. The higher population density, demographically higher level of education, and greater means for creative and emotional expression in the urban environment allows men living in the urban centers of the country to express themselves through other means not involving alcohol consumption, but the male dominated space of the social drinking environment paired with the excusing properties of alcohol consumption for intoxicated behavior allows rural and peri-urban men to express themselves emotionally with out damaging their performance of masculinity.

Production relations in drinking environments are also present in the opinions and narratives Swazi men have regarding how their drinking as being limited only by how much money they have. In a more covert way there are also narratives surrounding the idea of sharing alcohol consistently among a close group of friends in that there is a loose accounting system of who owes who drinks. Wealth is shared among friends while drinking, and all are expected to contribute, but not all at the same time, leading to very egalitarian ideas of who is drinking and who is buying at any particular time.

Swazi men may have wives, girlfriends, and/or children that they are expected to provide for, but drinking was always done as corresponding to how much money was on 
hand. While arguing that money is a key factor in alcohol consumption for men may be a stretch of the framing of production relations, in that male work is compensated more than female work, the other facets of symbolic relations and the crisis tendency surrounding production relations also involve the changing nature of production relations in Swaziland. As the symbolic and actual heads of their households, men were allowed to spend as much money as necessary on drinking. Yet higher alcohol content drinks were not sought after because they made the respondents too drunk too quickly, not because the price was too high or that such drinks have a higher status attached to them. The current social drinking environment stems from the traditional ideals of alcohol being an excuse to be social for long periods of time, and not as a means to show dominance or attain status over others through the purchasing of more expensive alcohol:

I prefer beer... I prefer the clean (alcoholic drinks), I just drink the buganu when it is made in my home....Except when I know you. Some people will put something that will make the buganu in higher alcohol, but stronger. But I'm not comfortable with that.

Interviewer: Why do you not (drink higher alcohol content alcohol)?

I get drunk too fast (while drinking that hard liquor)...When I just think of doing something, I just go (and do it). The (hard liquor) makes me go too fast. (Alan)

That respondents seek out specific drinks with a lower alcohol content over more alcoholic drinks illustrates a key difference between hegemonic masculine behavior in eSwatini compared to social drinking elsewhere in the region. In the Swazi social drinking context, the actual act of drinking frames the social and political discourse taking place among men drinking. Umcombotsi, with its low alcohol-by-volume, sorghum base, and ease of production, was the perfect drink for maintaining a hegemony 
of gendered power which allowed men to drink for long periods of time and discuss topics away from Swazi women (Magagula, 2013). Unlike in other social contexts of drinking and therefore other gender arenas of drinking, the quantity and quality of the alcohol being consumed is not a central component of the practice of hegemonic masculinity (Rich et.al., 2015). In the Swazi social drinking context, alcohol is used to excuse certain emotional, physical, and sexual displays, but how much one can drink does not support a person's claim to male hegemonic dominance.

Hegemonic masculinity, in either the traditional or hypermasculine form, is focused on sexual exploits. Such sexuality, and the tendency for risky sex as a means of increasing sexual pleasure, is exacerbated by alcohol consumption and social intoxication. Among the respondents, most said they used condoms constantly when having sex, but a number of respondents also said they had a tendency to not use condoms while engaging in intoxicated sex:

Sometimes I use, sometimes I don't....I like to use it, but at that time eish, yah, I am drunk. So I just don't think, hey there is a condom, no I just want this thing, and here is it, give it to me [right now]. (Alan)

Alan's response represents the internal reasoning of many of the respondents. Respondents have very distinctly outlined the public social drinking area: a large group of people, budding off into small groups, some women floating around between groups, alcohol being shared among friends, and possible violence between individuals and groups exacerbated by the crisis tendencies production relations are causing in other facets of masculinity. There is a continuing narrative discussed by the respondents that women drinking with men are of lower status compared to those women who stay at 
home, those women conforming to the emphasized femininity of the gender structure of eSwatini. So these women drinking are perceived to be lower status than others and are fought over, plied with drink and food and actual money, and the men so interested are drunk or maybe just more sober than the woman so they can control whether they use a condom or not. Such a use of power, as exacerbated by symbolic and production relations, and weighted with the emotional relations of desire and prejudice by men, create a fertile environment for risky sexual behavior to occur.

The gender structure of eSwatini puts women in an extremely dominated and exploited position. The expectations and narratives surrounding women in general and their actions specifically illustrate a disregard for female bodies and action. Add to this the gendered social drinking environment that focuses on male pleasure, hegemonic masculinity in power, production, emotional, and symbolic relations, and the crisis tendencies surrounding male labor being subverted by other economic factors, and the desires and safety of women fall so far below male attention that condom use is only at the behest of the male's sensual desires. If male behavior in the gendered social drinking environment is consistent through out the greater gender structure of eSwatini, then the power differences between men and women are at the center of the high HIV prevalence and incidence rates in this small country.

Other Masculinities and Drinking, or Not

As a reflection to illuminate the stratification of the actions found in the gendered social drinking environment, subordinated masculinity represents a less verbose, less social form of drinking. Only a few of the respondents interviewed drank alone, with the 
majority of the respondents drinking in public and part of groups that make up even larger groups of drinkers in public spaces. Fred practices a typical performance of those Swazi males who drink alone: quiet, soft-spoken, has inconsistent and low-skill manual labor jobs, has no steady girlfriend let alone wife, and does not own his own home. Fred talks about why he drinks alone and what he does while drinking:

I drink after work, about once a month...I buy from the bottle store and then sit and drink by myself (out in public at the bottle store)....(when I am drinking alone) I am busy thinking, about the future...People fight when they are drunk, (sometimes) they fight at a distance, shouting, being too loud....Those who are too talkative and those who are fighting while drunk, I can't stand them. (Fred)

The drinking behaviors of hegemonic masculinity are divisive and pervasive, taking up the entire drinking environment. Personal preference on sound and aggressiveness are pushed aside if social drinking wants to be engaged in. Carl goes on to the perceived rarity of drinking alone:

(Swazis) usually drink with other people....there is one guy, only one guy (I know who drinks alone.)...(I have drank by myself) a few times, when I was working in the capital. I never had a friend there, so I had to drink alone. (Carl)

Drinking alone is simply not preferable, even though the actual drinking must occur. The key difference between hegemonic and subordinate masculinities is the social dynamic and aspect of the drinking that is occurring. Most of the respondents were drinkers, and most of the drinkers drank socially and in public. The degree in which they are not only social but also engaging in assertive or aggressive behavior is the key linear distinction between hegemonic and subordinate masculinities in the gendered social drinking environment. Drinking socially means being socially outgoing, comfortable with aggression, possessing of enough money to pay for others' drinks, and staying out late. If 
one of those factors is not embraced by the individual, then they will find themselves in a position dominated by those performing a more hegemonic masculinity.

While Swazi masculinities in the gendered social drinking environment has a clear stratification between hegemonic and subordinate masculinity, the introduction of complicit masculinities into the drinking context points out another important factor in Swazi hegemonic masculinity: sexual behavior. Sexual behavior has been already shown to be a factor in hegemonic masculinity and is another environment in which men subordinate women, but these few respondents who do not explicitly aim to drink socially in a large groups show that alcohol consumption and the behaviors associated with it are a central factor in the masculinities of eSwatini, apart from how alcohol consumption influences and excuses sexual behavior in the gendered social drinking arena. Joseph talks about the role sexual behavior has on drinking and his own views on it:

I do not like men that are married who go and (get together with a woman who is not their wife)...Problems arises (when one man thinks that this other) man is with my woman (whom I was with sexually) three months ago, but they still need to just go fight with him (about it)...(Most men) normally fight when the bar closes down at around 12, fighting for certain women to at least go sleep with that woman that night. Because at that time when they are at the bar and would be spending money on that woman so that on that day they would actually go and have something together...They say that if there are three (men sitting together) and if two have girlfriends and one has a wife that the two (others that) have girlfriends (will) negotiate for (the married man) to have a girlfriend (to drink with, even if they have a wife)...Sometimes (men) find a lady that doesn't look all right when (they're) sober but the next day (even if they) found the lady looking so pretty when (they were) drunk....(Some men get more attracted to women when drinking, it's all about what you are into). Whether you like girls, but I like cars, most cars that I see while I'm drunk while watching a movie, they look so beautiful.

Joseph distinctly articulates how sexual behavior and the pursuit of sexual 
exploits are central to the gendered social drinking environment and an expression of hegemonic masculinity, but Joseph also equates how his behavior changes through drinking, likening sexual appetite or behavior to a personal preference of aesthetics and possession. But this sexual behavior also likens women participating in these drinking spaces as something that can be sought after and possessed, a narrative consistent with hegemonic masculinity. While complicit masculinity is not at the forefront of dominating women, nor is it a performance of a collection of qualities beneath that of hegemonic masculinity in the social drinking environment, complicit masculinity is a configuration of qualities and behaviors that still benefits from the overall subordination of women. Lewis talks about how he does not explicitly subordinate women, nor does he drink, but benefits from their subordination in general:

In Swazi culture women are forbidden to drink. All women are forbidden to drink...Because sometimes they end up doing something wrong, like selling their bodies to men...(Or sometimes I) see that when (especially women) are drunk they say anything without thinking maybe...(If a women speaks with out thinking first she may) not respect (her) male counterparts, and so with the Swazi law and culture it says that (women) must respect your male counterparts....(I do have try to have sex with women when they are drunk), if I know them already....it is very easy to have sex with a woman when she is drunk.

Lewis mentions how women are not allowed to drink in Swazi culture. While this is probably untrue in the overall Swazi society, and in the empirical daily realities of women in eSwatini, Lewis represents how Swazi men make it very clear that women are not sanctioned to be drunk at public drinking areas in the same ways men are. There are no laws against female drinking, and in my experience women do consume alcohol in the country, but cultural stigmas surrounding female behavior are very strong and controlling 
in Swazi culture (Fielding-Miller et.al., 2016). While women are excluded from or dominated over in these drinking environments, most Swazi men admit to having sex while drunk either with their wives and girlfriends, or other women they have a relationship with, but such a relationship is considered much lower status than being married or intending to be married (Fielding-Miller et.al., 2016) and is evidence of a class of pariah femininity in the gendered social drinking environment (Schippers, 2007). Lewis articulates the overt patriarchal dividend that all men directly benefit from their dominance over women in drinking environments, being able to freely engage in sex with or at least pursue women while they are intoxicated, but there are also a number of hidden benefits rendered from this dividend.

The most notable covert patriarchal dividend is that intoxicated men are not expected to use condoms when engaging in drunken sexual intercourse. While in general risking the potential for HIV infection would not be in their best physical interests, the performance of sexual power and dominance without facing increased responsibility (Rich et.al., 2015) and taking sexual risks as a factor in masculinity (Hunter, 2005) are consistent throughout the region. The respondents were quick to say that they used condoms during every sexual encounter, but there were some respondents who also said they could not be bothered to use a condom every time they had sex while drunk, which signifies that discussing HIV infection is still a sufficiently stigmatized subject to warrant an obscuring of the social reality surrounding unsafe intoxicated sex. Such a clean dichotomy of responses arguably points at a bigger issue of how intoxicated male behavior is not expected to conform to the same, safer standards as sober sexual behavior 
as is explored in other countries in the region (Rich et.al., 2015; Zablotska, et al., 2007).

This increase in self-reported risky sexual behavior is indicative of the benefits all men gain from the subordination of women and how drinking is a factor in increasing the incidence and prevalence of HIV in eSwatini.

Another form of subordinate masculinity is men who do not drink at all, or are completely absent from the social drinking environment and do not consume alcohol in private. This lack of consumption is usually explained in one of two ways. The first way such a lack of hegemonic male behavior is explained to still encompass drinking as a male behavior is that drinking is not seen as being fully religiously acceptable. eSwatini's official religion of Christianity provides a platform for men to explain others lack of drinking as a basis for religious practice:

Sometimes (a person's) religion says that they must not drink, some people say that. But some people are religious and still drink....(Those that think they have to abstain from alcohol to be religious) believe in God, but they do not work with God...They feel that when they are drinking they are not working in line with God, you cannot be drinking at the same time as believing in God....(But really it is only) if you are a pastor that you are not respected if you are taking alcohol. Everyone will take you for granted if you are taking alcohol (and are a religious leader)... it removes the respect on you because you are taking alcohol. (Alan)

Alan is drawing on themes trying to show how there is a murky connection between religious adherence and drinking, namely that they are mutually exclusive. Yet there is a way for a Swazi man to claim himself to be religious while still drinking through the weekends. Most respondents claimed to be religious, yet very few claimed they attended church with any regularity. Those who did attend services made a point to say that they drank only after going to church, if they drank on Sundays at all. That 
alcohol is not sold in stores on Sunday adds to the indistinct yet correlated link between alcohol use and religion. How religion operates on and within masculinities has been examined in other works focusing on religion and masculinities in South Africa (Burchardt, 2017; 2018) which finds such a distinction in the gendered social drinking environment as a facet of the alternative masculinity of abstaining from drinking, and supports how the two countries operate within a similar gender structure. While the deeper narratives and reasoning behind this link are beyond the purview of this paper, an alternative masculinity based on religious belief and identity is involved in how the gendered social drinking environment and religion operate on each other.

The second, but much less common, means in which a respondent claimed not to drink was due to the behavior of others. One respondent did not drink because alcohol consumption made him sick, but he still participated in the socializing aspects of drinking. The narratives surrounding non-drinking mostly involved the behavior of those drinking: drunk people were too loud, too aggressive, and acted foolishly. While some forms of subordinate masculinity were performed by drinking in private, other forms were performed by being present in the social drinking environment but not drinking. Being absent from the social drinking environment but consuming alcohol can be explained by others performing hegemonic masculinity by labeling drinking as an appropriate male action. Those who do not consume alcohol but are still present in the social drinking environment are folded much more carefully into the narratives surrounding the appropriateness of male behavior while drinking in particular and drinking being a social behavior performed by men and not women in general. 
As Lewis mentioned previously, he has benefited from the patriarchal dividend around women drinking, but Lewis was actively on drugs during his interview, which points out how possibly alcohol consumption itself is not the key component, but rather a more general drug consumption is a large part of eSwatini masculinities. That Lewis was a non-drinker but partook of other intoxicants while being social with other male drinkers is an example of how hegemonic masculine practices rub up against marginalized masculine practices: that being intoxicated in a public space is the acceptable behavior, and alcohol intoxication being the most acceptable means of intoxication. The link between the two performances of masculinity is that drugs, including alcohol, are a means to be social and engage in a physical and social space, and not that the quantity of the drug being consumed is an important factor in the performance of masculinity. Double Standards in the Social Drinking Environment and Emphasized Femininity in

\section{Swazi Culture}

In regards to the actual dominance of women in drinking spaces, many respondents talked openly about how they did not like the way women behaved while drinking. Every respondent who decried the behavior of drunk women either talked about actions that men also do or how their presence generates violence through men fighting over them. In the former case, respondents were reluctant to regard male behavior as equally destructive:

There are things that I don't like while (women) are drinking. (I will be sitting) outside of the shabeen, these women are coming out from the shabeen, and just taking off their pants and just pee in front of me, on the ground and that is not good. Another thing, when they are drunk, they promised to go with you and also promised to go with another man, and also promised to go with someone else, and 
that will end up causing a fight, (and) that is not good. Ahh, you can't blame a man (when he pees in front of you, though.) because a male can hide his thing like this...it is different for a woman she cannot hide it. (Burt)

Women walking around with their shorts, miniskirts, walking with other men that are not theirs, that do not belong to them. (Dennis)

Both of these quotes articulate a distinct double standard between male and female behavior in the social drinking in Swazi culture. That men are allowed to urinate publicly while women are not, despite the physical differences in conducting such a practice, illustrates how a number of male behaviors are ignored, if not actively supported, while women practicing the same behaviors are not tolerated by men. A second double standard surrounding engaging with multiple partners is also discussed by Dennis: men are supported in taking or at least courting multiple partners through the cultural practice of polygamy as well as a possible expression of a more modern masculinity as found in other cultures in the region (Gibbs, et.al., 2017). Due to rural areas being able to support more instances of traditional masculinity, by having enough space for men to own their own land to build a homestead on and raise a family, the closer confines of peri-urban eSwatini pressures men to engage in the more personal expressions of hypermasculinity such as increased sexual behavior. In the urban areas of the country, however, men interact with their female counterparts on a more even field in production and power relations, forcing men into more egalitarian expressions of their masculinity (Vijay, 2018).

As described above, fighting over women occurs with the women acting as the prize of violence:

(Something I do not like to see people doing while drinking is) fighting for 
women, fighting over women. (Sam)

Women who drink in general I think sometimes act irresponsibly...women go after other people's boyfriends (while drinking). (Kurt)

Women have a big problem...Mixing men, making men clash over them. (Michael)

In such instances, women were blamed as the cause of such behavior and not the men fighting. Such obscuring of the responsibility of action and double-standards are a blatant example of power relations between men and women. Other research has found that women were given responsibility for the action and inaction of men in social drinking establishments (Rich et.al., 2015) which adds to the obscuring of the responsibility of action and double-standards in the power and symbolic relations of the social drinking culture.

Respondents also talked about how women found at bars and bottle shops are expected to be prostitutes or engaging in transactional sex. That other women have been known to engage in prostitution at social drinking spots such as taverns and bottle stores, with respondents not speculating on what would lead women to do such things, colored much of the opinions of those respondents who talked about women being at public drinking environments:

(Women manipulate men into having sex with them and) every woman wants alcohol...The woman wants alcohol. That woman will use that thing that they have in them to a man to buy them alcohol. If the man will not do it...that is when they start touching you, that is when they start doing all of those things all over you. They know that in that way you will buy alcohol for them. (Victor)

Some women you find asking you for money for beer. When she is drinking and asks for money, the man has an opportunity to grab her. (Oscar) 
(Women can) sometimes end up doing something wrong, like selling their bodies to men...Not all of the (women who drink do that), but some....Drinking can cause a woman to sell herself. (Lewis)

Unlike men being expected to spend money while out drinking, women found frequently at drinking spots are presumed to be making money from the men found there. While the transaction of sex for alcohol and money may not be distinct and formal, men in social drinking establishments have expectations from women for whom they provide food, money, or alcohol (Rich et.al., 2015). The idea that women in a drinking space are always in a position to enact in transactional sex is a continuation of the production and power relations felt elsewhere in the gender structure of eSwatini (Fielding-Miller et.al., 2016).

Another way in which emotional relations are apparent in the gendered social drinking environment is in how men describe why they do not like women drinking around them. While most respondents talked about not minding drinking with women and specifically being more sexually aroused while drinking, they were also consistently against women being drunk near them. As shown in the words of respondents quoted earlier, the behavior a drunk male may engage in is more acceptable for a man than a woman. Such a distinction between males and females engaging in the same action but facing opposite results is also not uncommon in regional displays of hegemonic masculinity and the means of enforcing emphasized femininity on females (Mayeza, 2017).

The language respondents used while discussing their dissatisfaction with women being drunk in public drinking areas was more subjective and personal than when 
discussing other topics surrounding masculinity and the social drinking environment.

Respondents discussing how much they disliked women being drunk around them engaged in an emotional vocabulary that either highlighted perceived injustices of women choosing one romantic partner over another or making men feel inadequate for not being able to "keep" romantic partners whom they have brought to social drinking times and spaces. It is through the emotional relations between men and women in drinking establishments that we can see a desire by men to keep women out of these spaces based on the emotional strain of losing control over women based on other factors.

The symbolic expectations of women, in response to the symbolic dominance of hegemonic masculinity, articulate the emphasized femininity expected of Swazi women. Dominated, subjugated, and relegated to work solely in the homestead, there is a greater symbolic need for women to remain subordinate to men during changing economic conditions surrounding the crisis tendencies that eSwatini is facing. Alan and Edward talk about why women should not be out drinking with men:

Eish, when (women) have drunk, they do not control themselves in sexual behaviors. It is not good for a woman here in Swazi just to go (yelling), falling down. My mother, Eish, no no no no. (It is) not good for a mother to drink. I just cannot appreciate that that is my mother if I were to see her drinking. I would just go away. A woman drinking is not acting like a woman. (Alan)

It depends on how the female handles it. If she is harsh to me, I will try and talk with the person. If she is not harsh then we talk properly. Even if I am sober I interact with (women who are drinking. A harsh) female likes fighting. They talk things that are not okay, they go and talk to your wife about what it is that you were doing in the bar. Whatever is done in the bar should stay in the bar. (Edward)

The perfect Swazi wife, a symbol of emphasized femininity in eSwatini, stays at home, watches the children, and does the work needed to maintain the home while her 
husband can drink publicly to maintain his symbolic dominance. Polygamy is an undeniable factor in how women are thought of in comparison to men. That men are traditionally allowed to have as many wives as they can provide for forms an indelible symbolic link between men being central to the family, while women are seen as more peripheral due to many women being able to hold the status of wife at any one time. The symbolic peripheral nature of women in the family is in sharp contrast to the labor expected and required of women in the maintenance of the family and homestead. Therefore even in the family, thought to be the smallest social unit, there are means for men to maintain dominance, even in a multi-wife household through the man's symbolic and economic dominance of the women in his life. This symbolic link between the singularity of men and plurality of women to the all-important family unit replicates itself in sexual behavior.

A key component of emphasized femininity is how expected female behavior conforms to the needs and desires of hegemonic masculinity in the gender structure. To illustrate this, respondents also discussed what women were expected to be doing at the homestead while the men were out drinking:

When you are a female and you are married you're not supposed to take in alcohol, because of the responsibilities in the house who is going to do the work that is needed there? So I feel that you are not respected as a female if you drink alcohol because when you drink around people the people in society will not respect you. (Timothy)

(What I don't like about women drinking is that) some of the women that drink alcohol sometimes leave their husband in the house...So they leave their husband for another man because they get sexually aroused. Sometimes some of the women also tend to abandon their responsibilities for the intake of alcohol. (Richard) 
Long time ago, it was said that certain people were not allowed to drink... Young people that were still growing and women...No one would be able to look after the home if we all go and drink. (Nathan)

The narrative of women needing to be at home, not only having to work at home but actually needing to remain at home to maintain and be responsible for the homestead, is indicative of an overarching symbolic relationship between home, husband, and wife or wives in the gender structure of the county. The labor of women is expected to be centralized in the home, and such centralization is expected to be constant while male labor, energies, and status are not expected to be attached to one place constantly. With female labor being focused on maintaing the homestead, and male labor being focused on economic acquisition and sometimes physical defense, there is a clear symbolic relationship between women being a facet of the homestead that seeks to explain female domination in the overarching gender structure. It is from this symbolic relationship that the power, production, and emotional relations are rendered more clearly to be bent towards the dominance over women: women belong solely in the home, whereas men can be expected to be dominant in the home and out in public. With the increased proximity between men and women not just in living spaces but also in working spaces in urban areas, the symbolic connection between women and staying at home fades when the inherent humanity of women is made more apparent to men (Vijay, 2018). 


\section{Chapter 6: Discussion}

This study first sought to investigate the internal reasoning and external pressures Swazi men have in their drinking behavior. Not only did drinking turn out to be an important symbolic and cultural action undertaken by the individual, but also by the family unit as well, which links it into the greater gender structure of the country and culture. Discovering how drinking is an important part of the cultural fabric of eSwatini is an important contribution to academic knowledge of eSwatini and had not been replicated in any other academic research focusing on the country. The social drinking environment revealed a wide variety of masculinities that Swazi men could perform, including two forms of hegemonic masculinity supported by the stratification of a number of other subordinate masculinities. Due to what research has already been done in regards to male sexual behavior in changing cultural and economic environments, such information of the gender relations of the gendered social drinking environment move in ways predicted by other research in the region. Finally, due to the dominance of men and subjugation of women in the Swazi gender structure, the centrality of drinking to Swazi masculinities suggests an interesting direction for further research and prevention programs aimed at addressing the spread of HIV in eSwatini.

How alcohol myopia theory and motivational-expectation theory operate within Swazi men and their drinking behaviors ties in very distinctly into the masculinities they can perform. While neither theory fully explains what leads Swazi men to drink, the need for desired outcomes and a greater focus on immediate physical and social cues provide a solid reasoning behind male dominance of social drinking spaces. The possible 
therapeutic properties of alcohol consumption as a means of easing a discussion of emotions among men can be explained by either theory. Respondents talked about alcohol being necessary to working out frustrations from perceived and actual symbolic or sexual slights from women, either enacted on the individual or on the larger male group identity by allowing men to be vulnerable in a shared social space. Finally, the accentuation of the desired pleasures of large scale social interaction are the empirical outcomes of the more individualized theories behind drinking, which then mix with the narratives surrounding the centrality of drinking to Swazi masculinities. That Swazi male drinking behavior mimics the drinking behavior of South African men, at least in public drinking areas, situates this research more solidly relative to studies regarding alcohol consumption and masculinities in South Africa in particular and the region at large.

Drinking is a pervasive and culturally important behavior in eSwatini. Due to its centrality in a number of important family traditions and ceremonies, Swazis are acculturated to see drinking as a normal and necessary practice from a very young age. Since the family unit is a central element of the cultural environment and history of eSwatini, drinking is therefore seen to be of similar importance. Because men are symbolically, economically, and empirically situated at the center of the family unit, drinking, masculinity, and family overlap and intertwine with each other to form a symbolic importance for eSwatini and Swazi identity. Such centrality is also supported by the political and religious structure of the country, which shows how the gendered social drinking environment fits into the greater gender structure of the country. This research aimed to create a rough sketch of the importance of drinking in the country, specifically 
the acts of public social drinking and their importance to performances of masculinity.

The gendered social drinking environment also clearly illuminates a number of Swazi masculinities. Hegemonic masculinity embodies a very social, assertive, and sometimes aggressive drinking practice that operates on the production, power, emotional, and symbolic relations men enjoy in Swazi culture. While the gendered social drinking environment shows two different kinds of hegemonic masculinity- a traditional masculinity focused on responsibility and maintaining a family versus a more modern hypermasculinity focused on risky behavior, sexuality, and aggressiveness due to economic barriers preventing men from performing a traditional hegemonic masculinityboth focus on control, independence, critical decision making, and an overall dominance over women and female action. A number of subordinate masculinities exist to reflect the dominance hegemonic masculinity has in the gender structure of eSwatini. Some performances of subordinate masculinity in the gendered social drinking environment are more reserved, usually practiced through men drinking alone, in a small group, or at the periphery of large social drinking. Other subordinate masculinities socialize within the social drinking environment, benefiting from male dominance of a physical and social space, by taking advantage of other people's intoxication, but men performing these subordinate masculinities may not consume alcohol at all, or at least no within the gendered social drinking environment. Due to the cultural history marijuana use in eSwatini, some men may engage in a social, but alcohol abstaining form, of subordinate masculinity. These men may be intoxicated from dagga, but not engaging in the parallel cultural practice of alcohol consumption, while still in the social drinking space, is an 
important distinction between hegemonic masculinity and this specific performance of subordinate masculinity. Smoking of dagga does not have the social qualities of being an excuse for otherwise stigmatized behavior, unlike alcohol, meaning being socially intoxicated is an important factor for those performing hegemonic masculinity to excuse aggressive or sexual behavior in an effort to dominate the social drinking environment. Another form of subordinate masculinity is performed by those totally absent from alcohol consumption and the social drinking environment; this absence is explained away by the men performing hegemonic masculinity as either a physical ailment, naive sentiment, or incorrect translation of religious practice. By giving anecdotal and culturally empirical reasons for some men neither to drink nor be present in the social drinking environment, those performing hegemonic masculinity in the gendered social drinking environment can maintain that drinking is an inherently behavior, one that some men are bad at performing. By marginalizing some male behavior, the behavior of those neither drinking nor engaging in the social drinking environment, those performing hegemonic masculinity in the gendered social drinking environment maintain dominance and superiority over all male behavior in the culture.

The gender structure of any culture or society is hard to map accurately and completely. The all-encompassing and analytically abstract nature of the gender structure is a feature used to prevent the dominance of men over women from being seen as a pervasive and institutional issue. This dominance is expressed and supported by physical violence, aggression, and a fragile conception of one's respect and authority in social and cultural environments centered around an overall narrative of responsibility to the family. 
Yet due to the overall gender structure being expressed empirically in a number of social environments, if enough data is gathered the abstract and encompassing gender structure of a culture can be better articulated and illuminated through the understanding of the narratives and behaviors at play in one or more of its empirical social environments. Because enough data was collected in the peri-urban social drinking environment of this part of eSwatini, the overall gender structure of Swazi culture, to some extent, was illuminated and analyzed.

The male dominance of the gendered social drinking environment allowed narratives surrounding women as held by men to be clearly illuminated. The social drinking space is symbolically and physically maintained as a male focused environment, allowing men to express themselves without reprisal and to excuse misbehavior, as identified by other men, as a factor of drinking. When discussing this gendered social environment, the respondents were able to articulate an emphasized femininity not only for women found in the social drinking space but also those who are specifically left behind in the homestead. While the existence of a hegemonic femininity, a parallel gender structure created to oppose male dominance and stratify female gendered behavior, has been theorized and empirically found in other cultures, no such hegemonic femininity was reported by the men in this research. Other research in the region on gender performance, hegemonic masculinity, and the domination of females in gender structures of other countries has likewise not yielded empirical evidence of hegemonic femininity. Such a lack of evidence does not necessarily mean there are no behaviors, narratives, nor practices that could constitute a resistance to male dominance over and 
internal stratification of women, but this study only finds evidence of an emphasized femininity as expressed by the men in the social drinking gender regime.

With other countries in the area undergoing similar high rates of HIV prevalence and incidence, one of the main reasons eSwatini is experiencing the highest rate of HIV per capita in the region has to do with the gender structure of the country. The tensions between the traditional hegemonic masculinity and the more modern hypermasculinity is a potential reason for the increased HIV rates in the region, with eSwatini being the highest in the world due to its gender structure being so focused on domination of women through the centrality of men in the family structure. That it is a total monarchy, that promotes the dominance of men in power, production, emotion, and symbolic relations in the political and societal infrastructure of the country, cannot be ignored in trying to understand the highest rate of HIV infection in an already high HIV prevalence and incidence region.

By focusing on performances of masculinity to not only decrease rates of alcohol abuse but also HIV in the country, non-governmental organizations in eSwatini and other countries in the region could utilize this study to better understand and change the behaviors underlying many health risks. This study draws a clear connection between risky sexual behavior, drinking, and performances of masculinity in the country that no other study has been able to illustrate. By addressing the underlying reasoning of alcohol consumption in Swazi men, that of a performance of masculinity in a very female dominating gender structure, institutions could use this study to cheaply and effectively address health concerns in eSwatini. 


\section{$\underline{\text { References }}$}

1. Bhana, D., \& Mayeza, E. (2016). We don't play with gays, they're not real boys ... they can't fight: Hegemonic masculinity and (homophobic) violence in the primary years of schooling. International Journal of Educational Development,51, 36-42. doi:10.1016/j.ijedudev.2016.08.002

2. Bhembe, M. (2010, March 12). Swazi dagga a threat to 2010 World Cup. Swazi Times. Retrieved April 17, 2019, from http://www.swazilive.com/Swaziland_News/Swaziland_News_Stories.asp? News_id=1514

3. Brear, Michelle, and Dawn Bessarab. "Perspectives on Intimate Partner Violence in Swaziland amongst 18-29-Year-Old Men Undergoing Medical Circumcision." Culture, Health \& Sexuality, vol. 14, no. 1, 2012, pp. 31-43., doi:10.1080/13691058.2011.607903.

4. Breiding, Matthew J, et al. "Risk Factors Associated with Sexual Violence towards Girls in Swaziland." Bulletin of the World Health Organization, vol. 89, no. 3, 2011, pp. 203-210., doi:10.2471/blt.10.079608.

5. Burchardt, M. (2017). Saved from hegemonic masculinity? Charismatic Christianity and men's responsibilization in South Africa. Current Sociology,66(1), 110-127. doi:10.1177/0011392117702429

6. Burchardt, Marian (2018) Masculinity, sexual citizenship and religion in postapartheid South Africa: a field-theoretical approach, Citizenship Studies, 22:6, 569-585, DOI: 10.1080/13621025.2018.1494902 
7. Buseh, Aaron G. "Patterns of Sexual Behaviour among Secondary School Students in Swaziland, Southern Africa." Culture, Health \& Sexuality, vol. 6, no. 4, 2004, pp. 355-367., doi:10.1080/13691050410001668711.

8. CDC and PEPFAR. "Swaziland HIV Incidence Measurement Survey 2: A Population-Based HIV Impact Assessment.” SHIMS2, October 2017. http://phia.icap.columbia.edu/countries/ swaziland/.

9. Chipamaunga, Shalote, et al. "An Assessment of Sex Work in Swaziland: Barriers to and Opportunities for HIV Prevention among Sex Workers.” SAHARA-J: Journal of Social Aspects of HIV/AIDS, vol. 7, no. 3, 2010, pp. 44-50., doi:10.1080/17290376.2010.9724968.

10. Cockcroft, Anne, et al. "What Happened to Multiple Sexual Partnerships in Swaziland? Analysis of Five Linked National Surveys between 2002 and 2008." AIDS Care, vol. 22, no. 8, 2010, pp. 955-960., doi:10.1080/09540121.2010.482123.

11. Cox, W., Klinger, E. “A Motivational Model of Alcohol Use.” Journal of Abnormal Psychology 1988, Vol. 97, No. 2, 168-180. Copyright 1988 by the American Psychological Association, Inc.

12. Daly, John L. "Gender Equality Rights versus Traditional Practices: Struggles for Control and Change in Swaziland." Development Southern Africa, vol. 18, no. 1, 2001, pp. 45-56., doi:10.1080/03768350124525.

13. Dermen, K.H., Cooper, M.L. and Agocha, V.B 1998. "Sex-related alcohol expectancies as moderators of the relationship between alcohol use and risky sex 
in adolescents." Journal of Studies on Alcohol 59, (1): 71-77.

14. Eagly, Alice Hendrickson. Sex Differences in Social Behavior: A Social-role Interpretation. Hillsdale, NJ: L. Erlbaum Associates, 1987. Print.

15. Fielding-Miller, R., Dunkle, K. L., Jama-Shai, N., Windle, M., Hadley, C., \& Cooper, H. L. (2016). The feminine ideal and transactional sex: Navigating respectability and risk in Swaziland. Social Science \& Medicine,158, 24-33. doi:10.1016/j.socscimed.2016.04.005

16. Feirman, Shari. "Men's Susceptibility to HIV in Swaziland." Culture, Health \& Sexuality Vol. 14, No. 7, August 2012, 723-735

17. Gibbs, A., Jewkes, R., \& Sikweyiya, Y. (2017). "I Tried to Resist and Avoid Bad Friends". Men and Masculinities,21(4), 501-520. doi:10.1177/1097184x17696173

18. Gillis, D. (1999). The kingdom of Swaziland studies in political history. Westport, Conn.: Greenwood Press.

19. Goldman, Mark S., Roehrich, Laurie. "Alcohol expectancies and sexuality." Alcohol Health \& Research World, 0090838X, 1991, Vol. 15, Issue 2

20. Government of the Kingdom of Eswatini. Ministry of Health. (2017). SWAZILAND HIV INCIDENCE MEASUREMENT SURVEY 2: A POPULATIONBASED HIV IMPAC ASSESSMENT SHIMS2 2016-2017.

21. Graham, K., Schmidt, G., Gillis, K., 1996. Circumstances when drinking leads to aggression: an overview of research findings. Contemp. Drug Probl. 23, 493-558. http://refhub.elsevier.com/S0376-8716(13)00360-8/sbref0060

22. Hamburger, Merle E., et al. "Childhood Maltreatment and Early Alcohol Use 
Among High-Risk Adolescents." Journal of Studies on Alcohol and Drugs, vol. 69, no. 2, 2008, pp. 291-295., doi:10.15288/jsad.2008.69.291.

23. Hamlall,Vijay (2018) Heterosexual relationships among young black men in the construction of masculinity at a South African university, Social Dynamics, 44:2, 306-321, DOI:10.1080/02533952.2018.1481686

24. Hatcher, Abigail M., et al. "Intimate Partner Violence among Rural South African Men: Alcohol Use, Sexual Decision-Making, and Partner Communication." Culture, Health \& Sexuality, vol. 16, no. 9, 2014, pp. 10231039., doi:10.1080/13691058.2014.924558.

25. Hendershot, C.S. et.al. "Alcohol Use, Expectancies, and Sexual Sensation Seeking as Correlates of HIV Risk Behavior in Heterosexual Young Adults.” Psychology of Addictive Behaviors. Copyright 2007 by the American Psychological Association 2007, Vol. 21, No. 3, 365-372

26. Hosier, Steven G., and W. Miles Cox. "Personality and Motivational Correlates of Alcohol Consumption and Alcohol-Related Problems among Excessive Drinking University Students." Addictive Behaviors, vol. 36, no. 1-2, 2011, pp. 87-94., doi:10.1016/j.addbeh.2010.08.029.

27. Hunter, Mark (2005) Cultural politics and masculinities: Multiple-partners in historical perspective in KwaZulu-Natal, Culture, Health \& Sexuality: An International Journal for Research, Intervention and Care, 7:4, 389-403

28. Hunter M. 2007. The changing political economy of sex in South Africa: the significance of unemployment and inequalities to the scale of the AIDS pandemic. 
Soc. Sci. Med. 64(3):689-700

29. Jones, Lynne. "Sexual Discourse and Decision-Making by Urban Youth in AIDSAfflicted Swaziland.” African Journal of AIDS Research, vol. 5, no. 2, 2006, pp. 145-157., doi:10.2989/16085900609490375.

30. Kalichman, S., Simbayi, L., Kaufman, M., Cain, D. and Jooste, S 2007. “Alcohol use and sexual risks for HIV/AIDS in sub-Saharan Africa: systematic review of empirical findings." Prevention Science 8, (2): 141-151.

31. Kiwanuka, Noah, et al. "Population Attributable Fraction of Incident HIV Infections Associated with Alcohol Consumption in Fishing Communities around Lake Victoria, Uganda." Plos One, vol. 12, no. 2, 2017, doi:10.1371/journal.pone.0171200.

32. Krishnan, S., et.al. "Do changes in spousal employment status lead to domestic violence? Insights from a prospective study in Bangalore, India." Social Science \& Medicine 70 (2010) 136-143.

33. Kunene, P. (2017, August 7). Drunk Drivers Record High Alcohol Readings. Swazi Observer, https://www.pressreader.com/swaziland/swaziobserver/20170807/281745564477747.

34. Kuper, Hilda. An African Aristocracy; Rank among the Swazi. London: Published for the International African Institute by the Oxford UP, 1961. Print.

35. Kuper, Hilda. The Swazi. London: International African Institute, 1952. Print.

36. Labrie, Joseph W., et al. "Expectancies Specific to Condom Use Mediate the Alcohol and Sexual Risk Relationship." Journal of Sex Research, vol. 39, no. 2, 
2002, pp. 145-152., doi:10.1080/00224490209552134.

37. Leigh, Barbara C., and Ron Stall. "Substance Use and Risky Sexual Behavior for Exposure to HIV: Issues in Methodology, Interpretation, and

Prevention.” American Psychologist, vol. 48, no. 10, 1993, pp. 1035-1045., doi:10.1037/0003-066x.48.10.1035.

38. Lesch, E. and Casper, R. “'Drinking with respect': Drinking constructions of men who live in a Cape Winelands farm community in South Africa." Journal of Health Psychology 2017, Vol. 22(4) 409-421.

39. Lien, Lars, et al. "Alcohol Use in South Sudan in Relation to Social Factors, Mental Distress and Traumatic Events." BMC Public Health, vol. 16, no. 1, 2016, doi:10.1186/s12889-016-3605-9.

40. Lynch, I., \& Clayton, M. (2016). 'We go to the bush to prove that we are also men': Traditional circumcision and masculinity in the accounts of men who have sex with men in township communities in South Africa. Culture, Health \& Sexuality, 19(3), 279-292. doi:10.1080/13691058.2016.1215527

41. MacDonald, Tara K., et al. "Alcohol, Sexual Arousal, and Intentions to Use Condoms in Young Men: Applying Alcohol Myopia Theory to Risky Sexual Behavior." Health Psychology, vol. 19, no. 3, 2000, pp. 290-298., doi:10.1037//0278-6133.19.3.290.

42. Magagula, M. (2013, September 1st). 60\% Swazis Drink Umcombotsi. Times of Swaziland, http://www.times.co.sz/news/90970-60-swazis-drinkumcombotsi.html. 
43. Mahdi, Mohammed Ali. An Exploratory Study of the Behaviors and Practices that may Increase HIV Risk among Pregnant and Lactating Women in Communities in Swaziland. Mbabane: Elizabeth Glaser Pediatric AIDS Foundation, 2015.

44. Malhorta, N., Yang, J. "Risky Behavior and HIV Prevalence Among Zambian Men.” J. Biosoc. Sci., (2011) 43, 155-165, Cambridge University Press, 2010

45. Matsebula, B. (2002, January 29). Swazi police target marula drinkers. $B B C$ News, http://news.bbc.co.uk/2/hi/africa/1789661.stm.

46. Matsebula, J. S. M. A History of Swaziland. Cape Town: Longman Southern Africa, 1972. Print.

47. Mayeza, Emmanuel (2017) 'Girls don’t play soccer': children policing gender on the playground in a township primary school in South Africa, Gender and Education, 29:4, 476-494, DOI: 10.1080/09540253.2016.1187262

48. McCrady, Barbara S. "To Have But One True Friend: Implications for Practice of Research on Alcohol Use Disorders and Social Network." Psychology of Addictive Behaviors, vol. 18, no. 2, 2004, pp. 113-121., doi:10.1037/0893$164 x \cdot 18.2 .113$.

49. Mdluli, M. (2016, July 25). SA Man vows to never drink, drive. Swazi Observer, https://www.pressreader.com/swaziland/swaziobserver/20160725/281736973811612.

50. Medich, Melissa, et.al. (2018) The pull of soccer and the push of Xhosa boys in an HIV and drug abuse intervention in the Western Cape, South Africa, 
SAHARA-J: Journal of Social Aspects of HIV/AIDS, 15:1, 187-199, DOI:

$10.1080 / 17290376.2018 .1541024$

51. Monitoring and Evaluation Unit (MEU), Strategic Information Department. Annual Non-Communicable Diseases Program Report. Mbabane: Kingdom of eSwatini Ministry of Health, 2015.

52. Moosa, Shaaista \& Bhana, Deevia (2018) 'They won't take you as a man, as a real man' why men can't teach young children in foundation phase, International Journal of Inclusive Education, 22:6, 577-593, DOI:

$10.1080 / 13603116.2017 .1390002$

53. Morojele, N.K. et.al. "Alcohol use and sexual behaviour among risky drinkers and bar and shebeen patrons in Gauteng province, South Africa." Social Science \& Medicine 62 (2006) 217-227

54. Morojele, Neo. A NEW CHALLENGE FOR SOUTHERN AFRICA: Health, Economic and Social Costs of Alcohol Use in Southern Africa. Johannesburg: Medical Research Council of South Africa, 2015.

55. Motsa, T. (2016, September 20). Is Legalizing Dagga in Swaziland Good or Bad? Read About Both Sides Before You Judge. Eswatini 24. Retrieved April 17, 2019, from https://eswatini24.com/is-legalizing-dagga-in-swaziland-good-or-bad-readabout-both-sides-before-you-judge/

56. Orubuloye, I.o., et al. "Perceived Male Sexual Needs and Male Sexual Behaviour in Southwest Nigeria." Social Science \& Medicine, vol. 44, no. 8, 1997, pp. 11951207., doi:10.1016/s0277-9536(96)00254-7. 
57. Pascoe, C. J., and Tristan Bridges. Exploring Masculinities: Identity, Inequality, Continuity and Change. 2016.

58. Please Bring Back the Death Sentence. (2018, January 10). Times of Swaziland, http://www.times.co.sz/letters/116535-please-bring-back-the-death-sentence.html.

59. Polgreen, L. (2012, August 14). Grandmas Grow Gold in Swaziland. The New York Times. Retrieved April 17, 2019, from https://www.nytimes.com/2012/08/15/world/africa/grandmothers-growmarijuana-in-swaziland-to-support-families.html

60. Rich, E. P., Nkosi, S., \& Morojele, N. K. (2015). Masculinities, alcohol consumption, and sexual risk behavior among male tavern attendees: A qualitative study in North West Province, South Africa. Psychology of Men \& Masculinity, 16(4), 382-392. doi:10.1037/a0038871

61. Root, R. "Religious Participation and HIV-Disclosure Rationales among People Living with HIV/AIDS in Rural Swaziland."African Journal of AIDS Research, vol. 8, no. 3, 2009, pp. 295-309., doi:10.2989/ajar.2009.8.3.6.927.

62. Root, R. "Situating Experiences of HIV-Related Stigma in Swaziland." Global Public Health, vol. 5, no. 5, 2010, pp. 523-538., doi:10.1080/17441690903207156.

63. Risman, Barbara J and Georgiann Davis (2013). From sex roles to gender structure. Current Sociology 2013 61: 733, DOI: 10.1177/0011392113479315

64. Sartor, Carolyn E., et al. "Childhood Sexual Abuse and the Course of Alcohol Dependence Development: Findings from a Female Twin Sample.’Drug and 
Alcohol Dependence, vol. 89, no. 2-3, 2007, pp. 139-144., doi:10.1016/j.drugalcdep.2006.12.022.

65. Schippers, M. (2007). Recovering the feminine other: Masculinity, femininity, and gender hegemony. Theory and Society,36(1), 85-102. doi:10.1007/s11186-0079022-4

66. Schraufnagel, Trevor J., et al. "Childhood Sexual Abuse in Males and Subsequent Risky Sexual Behavior: A Potential Alcohol-Use Pathway." Child Abuse \& Neglect, vol. 34, no. 5, 2010, pp. 369-378., doi:10.1016/j.chiabu.2009.08.013.

67. Set Drinking Age at 21. (2013, November 27). Times of Swaziland, http://www.times.co.sz/feature/93642-set-drinking-age-at-21.html.

68. Shongwe, N. (2018, January 14). Cops vandalise flat, leave with shabeen tenants fridge. Times of Swaziland, http://www.times.co.sz/news/116620-cops-vandaliseflat $\% 2 \mathrm{C}$-leave-with-shebeen-tenant $\% \mathrm{E} 2 \% 80 \% 99$ s-fridge.html.

69. Simatende, Protus \& Gadaga, Henry \& Nkambule, Stanley \& Siwela, Muthulisi. (2015). Methods of Preparation of Swazi Traditional Fermented Foods. Journal of Ethnic Foods. 2. 10.1016/j.jef.2015.08.008.

70. Simelane, Hamilton Sipho. “'Sharing My Bed with the Enemy': Wives and Violent Husbands in Post-Colonial Swaziland." Journal of Contemporary African Studies, vol. 29, no. 4, 2011, pp. 493-512., doi:10.1080/02589001.2011.601045.

71. Slopen, Natalie, et al. "Sex, Stressful Life Events, and Adult Onset Depression and Alcohol Dependence: Are Men and Women Equally Vulnerable?" Social Science \& Medicine, vol. 73, no. 4, 2011, pp. 615-622., 
doi:10.1016/j.socscimed.2011.06.022.

72. Steele, C.M., Josephs, R.A. "Alcohol Myopia: Its Prized and Dangerous Effects." C1990. American Psychological Association, Inc. 0003-066X/90./\$00.75 Vot. 45, No. 8. 921-933

73. Stickley, Andrew, et al. "Adolescent Binge Drinking and Risky Health Behaviours: Findings from Northern Russia." Drug and Alcohol Dependence, vol. 133, no. 3, 2013, pp. 838-844., doi:10.1016/j.drugalcdep.2013.08.028.

74. Taylor, Myra, et al. "Screening Caregivers of Children for Risky Drinking in KwaZulu-Natal, South Africa." Maternal and Child Health Journal, vol. 20, no. 11, 2016, pp. 2392-2401., doi:10.1007/s10995-016-2066-1.

75. Teunissen, Hanneke A., et al. “Adolescents' Conformity to Their Peers' ProAlcohol and Anti-Alcohol Norms: The Power of Popularity." Alcoholism: Clinical and Experimental Research, vol. 36, no. 7, 2012, pp. 1257-1267., doi:10.1111/j.1530-0277.2011.01728.x. (Teunissen, et al., 2012)

76. Thakarar, Kinna, et al. "Alcohol Consumption in Ugandan HIV-Infected Household-Brewers Versus Non-Brewers." AIDS and Behavior, vol. 20, no. 10, 2016, pp. 2408-2417., doi:10.1007/s10461-016-1421-y.

77. Tomsen, S. “A TOP NIGHT: Social Protest, Masculinity and the Culture of Drinking Violence." British Journal of Criminology, vol. 37, no. 1, 1997, pp. 90102., doi:10.1093/oxfordjournals.bjc.a014152.

78. UN Media IRIN. (2007, March 27). Swaziland addresses heavy-drinking reputation. Afrol NEWS, http://www.afrol.com/articles/24872. 
79. Weiser, S.D., K. Leiter, D.R. Bangsberg, L.M. Butler, F. Percy-de Korte, Z. Hlanze, N. Phaladze, V. Iacopino, and M. Heisler. 2007. Food insufficiency is associated with high-risk sexual behavior among women in Botswana and Swaziland. PLoS Medicine 4, no. 10: 1589-97.

80. Wen, Xiao-Jun, et al. "Prevalence of HIV Risk Behaviors Between Binge Drinkers and Non-Binge Drinkers Aged 18- to 64-Years in US, 2008." Journal of Community Health, vol. 37, no. 1, 2011, pp. 72-79., doi:10.1007/s10900-0119418-y.

81. World Health Organization. Country Profiles: Africa. New York: World Health Organization, 2011.

82. Zablotska, Iryna B., et al. "Alcohol Use, Intimate Partner Violence, Sexual Coercion and HIV among Women Aged 15-24 in Rakai, Uganda.” AIDS and Behavior, vol. 13, no. 2, 2007, pp. 225-233., doi:10.1007/s10461-007-9333-5.

83. Zamberia,Agostino M "Sexual activity and condom use among people living with HIV in Swaziland." African Journal of AIDS Research. 2009. 8:1, 69-81, DOI: 10.2989/ A JAR.2009.8.1.8.721

84. Ziyane, Isabella S., and Valerie J. Ehlers. "Swazi Men’s Contraceptive Knowledge, Attitudes, and Practices." Journal of Transcultural Nursing, vol. 18, no. 1, 2007, pp. 5-11., doi:10.1177/1043659606294190. 


\section{Appendix: Survey Instrument}

1. Introductions

(a) How are you doing today?

(b) Are we getting enough rain this year?

(c) Do you know the Moya Centre?

i. Do you know what they do?

ii. Have you worked with them before?

(d) Do you know of the Peace Corps?

i. Do you know what they do?

ii. Have you worked with them before?

(e) Have you ever participated in a research project before?

i. Do you have any questions about what I am collecting?

ii. Do you have any questions about the work I do here in Swaziland?

2. Family, Education, Work

(a) Do you live here in Mahlanya?

(b) Did you grow up here or somewhere else in Swaziland?

(c) What was it like to grow up in your family?

i. Do you visit them often? 
ii. How many siblings do you have?

(d) Where did you go to school?

i. What was your favorite subject?

(e) Do you live with family here?

(f) What kind of work do you do here?

i. Have you done this work before or is it new to you?

(g) Do you practice any religion?

(h) Are you married?

i. Do you have any children?

ii. Does your family live here in Mahlanya with you?

3. Talking About Swaziland

(a) What would you tell someone about Swaziland that has never been here before?

(b) Have you been to any other countries?

(c) Would you move to another country and live there for a time?

(d) What do you like most about Swaziland?

i. What do you like most about being a Swazi man?

(e) Is there anything about Swaziland that you would change?

4. Recreation 
(a) Have you met some people, made some friends here in Mahlanya?

(b) Do you like football?

i. What's your favorite team? Are they doing well this year?

(c) What do you like to do for fun after work?

\section{Drinking}

(a) What do Swazis usually drink when drinking alcohol?

(b) How do you view other people drinking in the community?

i. Is there anything Swazis do while drinking that you don't like?

ii. Things you don't like about Swazi men drinking?

iii. Things you don't like about Swazi women drinking?

(c) Do Swazis usually drink alone or with other people?

(d) Is there anything in Swazi culture that says certain people shouldn't drink?

(e) What do you commonly see people doing while drinking?

i. Do they socialize, watch football, walk around?

(f) Why do you think people drink?

i. Why do you think men drink?

ii. Why do you think Swazis drink?

iii. Why do you think Swazi men drink? 
(g) Do you drink at all?

i. Do you drink with others or by yourself?

(h) When did you start drinking?

(i) What do you usually drink?

(j) Do you do anything in particular while drinking?

i. When you're with people what topics do you usually talk about?

(k) When do you drink?

i. Are there any times of the day or week that you specifically do not drink during?

ii. Are there any special occasions you drink at or for?

(1) Where do you drink?

i. Where do you purchase alcohol?

(m) Do people treat you any differently when you are drinking?

\section{On Not Drinking}

(a) Do you have any particular reason for not drinking alcohol?

(b) Do any of your family members drink?

(c) Do you have any friends that drink?

(d) Do you socialize with friends or family when they are drinking? 


\section{And Women}

(a) Do you know any women who drink?

(b) What do you think about women who drink?

(c) Do you drink with women?

i. How do you interact with them when you are drinking or drunk?

ii. Do you interact with women differently while sober than when you are drunk?

(d) Do you ever have sex while drunk?

i. Are you more sexually driven while drinking or drunk?

ii. Do you use protection when drunk? 